\title{
LUNG FUNCTION DETERMINANTS AND MORTALITY OF CHILDREN AND ADOLESCENTS WITH CYSTIC FIBROSIS IN SOUTH AFRICA 2007-2016
}

\author{
Natalie Joëlle Vandenbroucke \\ Student number: VBRNAT003
}

In partial fulfilment for the degree of

\section{MMed (Master of Medicine Paediatrics)}

Faculty of Health Sciences

UNIVERSITY OF CAPE TOWN

\section{Faculty of Health Sciences Declaration of Originality}

This research report is my original work. Neither the whole work nor any part of it has been, is being, or is to be submitted for another degree to any other university. None of this work has been published in any format prior to registration for the above-mentioned degree.

\section{Date of Submission:}

Supervisor: Professor Brenda Morrow

Co-supervisor: Dr Marco Zampoli

Correspondence: nataliejkuiper@gmail.com 
The copyright of this thesis vests in the author. No quotation from it or information derived from it is to be published without full acknowledgement of the source. The thesis is to be used for private study or noncommercial research purposes only.

Published by the University of Cape Town (UCT) in terms of the non-exclusive license granted to UCT by the author. 


\section{Table of Contents}

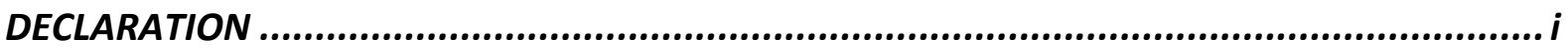

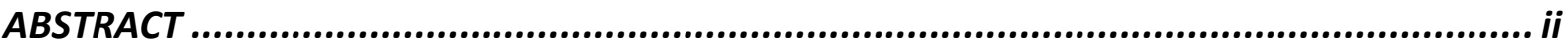

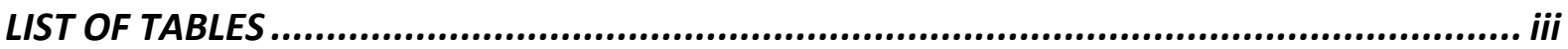

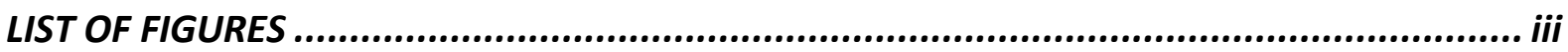

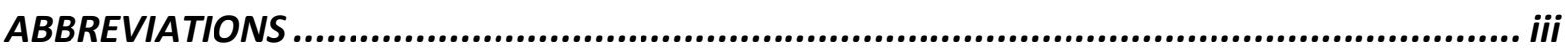

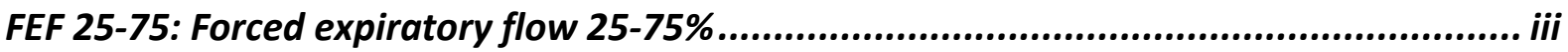

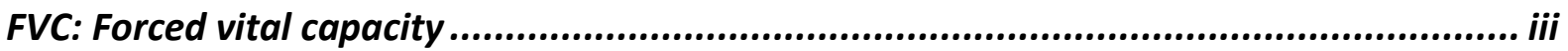

GLI: Global Lung Function Initiative...................................................................... iii

HREC: Human research ethics committee ................................................................... iii

LMIC: Low-middle income country ......................................................................... ii

PFT: Pulmonary function test ............................................................................. iii

ACKNOWLEDGEMENTS AND CONTRIBUTIONS...................................................... iv

CHAPTER 1: INTRODUCTION AND LITERATURE REVIEW ................................. Chapter 1.1

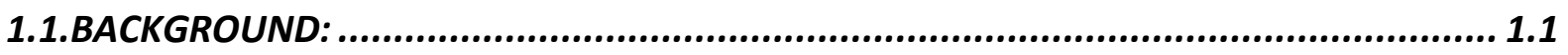

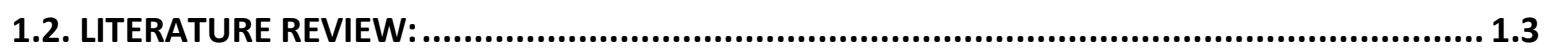

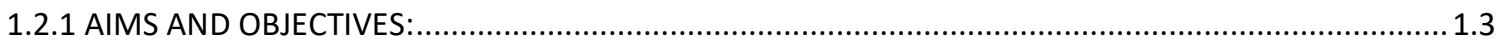

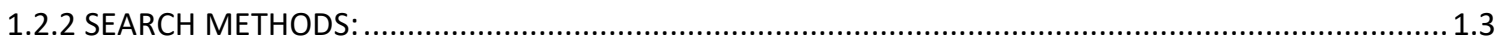

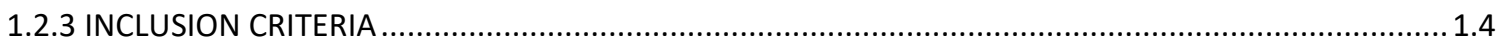

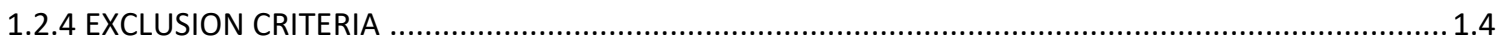

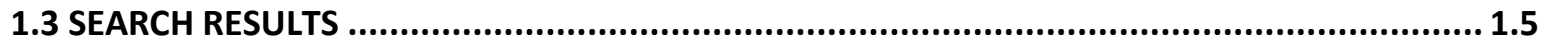

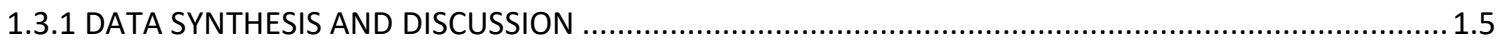

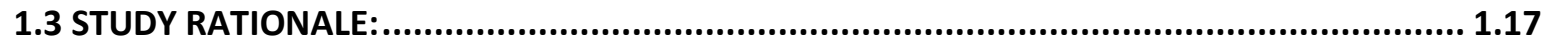

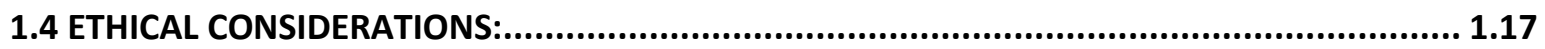

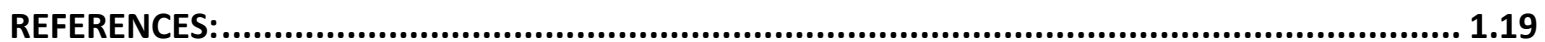

CHAPTER 2: PUBLICATION-READY MANUSCRIPT ........................................... Chaper 2.1

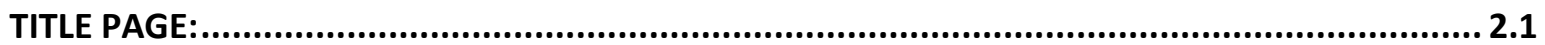

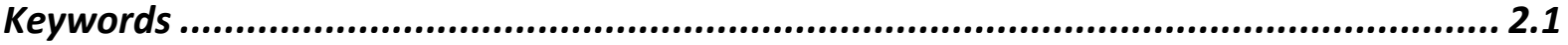

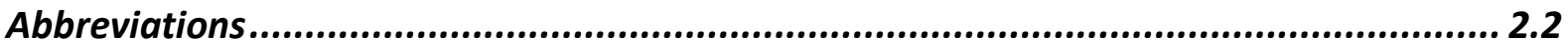

ABSTRACT:

INTRODUCTION:

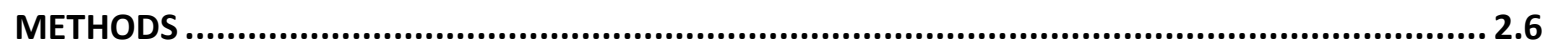

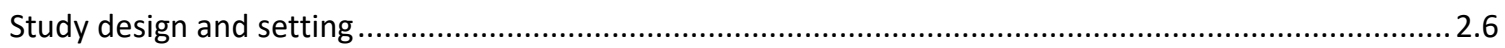

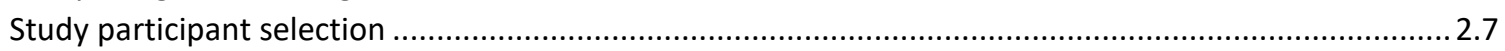

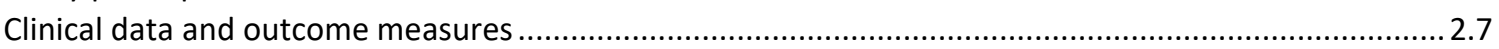

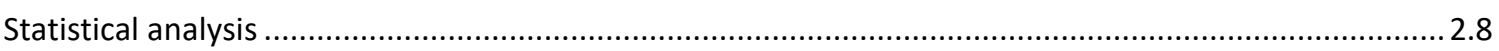

$\begin{array}{lr}\text { VBRNATOO3 MMed (Paediatrics) } & 2\end{array}$ 


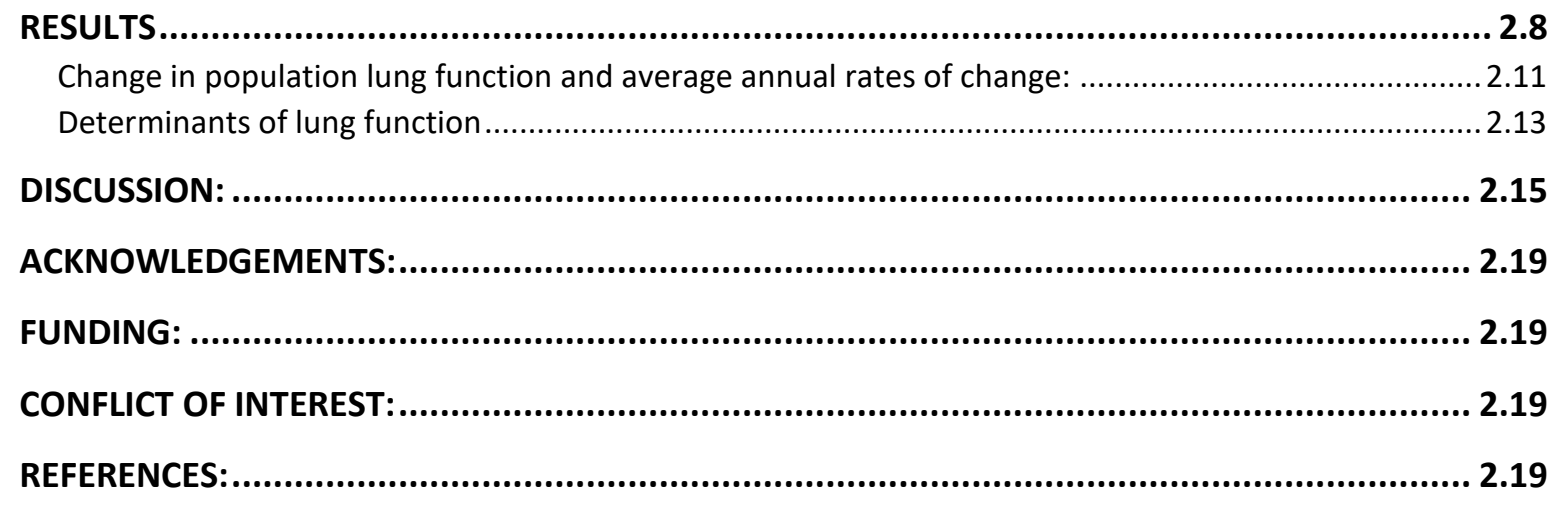

APPENDIX 1: Human Research Ethics Committee (HREC) approval..................Appendix 1.1

APPENDIX 2: Questionnaire/data capture instrument(s) .............................Appendix 2.1

APPENDIX 3: AUTHOR GUIDELINES South African Medical Journal (SAMJ)....... Appendix 3.1 


\section{DECLARATION}

I, Dr Natalie Joëlle Vandenbroucke, hereby declare that the work on which this dissertation/thesis is based is my original work (except where acknowledgements indicate otherwise) and that neither the whole work nor any part of it has been, is being, or is to be submitted for another degree in this or any other university.

I empower the university to reproduce for the purpose of research either the whole or any portion of the contents in any manner whatsoever.

Signature:

Signed by candidate

Date: $\quad . . . . .28 / 09 / 2019$ 


\title{
ABSTRACT
}

\section{LUNG FUNCTION DETERMINANTS AND MORTALITY OF CHILDREN AND ADOLESCENTS WITH CYSTIC FIBROSIS IN SOUTH AFRICA 2007-2016}

\author{
Authors: Natalie Vandenbroucke; Marco Zampoli; Brenda Morrow
}

Objectives: Cystic fibrosis (CF) is one of the commonest inherited disorders in South Africa, affecting all population groups. Progressive pulmonary disease with declining forced expiratory volume in one second (FEV1) is the main predictor of morbidity and mortality in individuals with CF. This study aimed to describe the change in lung function, nutritional status and mortality of children and adolescents with CF, attending the Red Cross War Memorial Children's Hospital (RCWMCH) CF Clinic and to identify factors associated with poor pulmonary function outcomes and mortality.

Methods: A retrospective study was conducted of the clinical records and annual pulmonary function tests, with matched body mass index (BMI), of children between 5 and 18 completed years of age attending the RCWMCH CF clinic in Cape Town, South Africa, between January 2007 and December 2016.

Results: A total of 143 study participants (51.4\% male; median age at diagnosis 5.5 months) were included. Population mean FEV1 and body mass index (BMI) Z scores improved from $-2.5 \pm 1.70$ to $-1.9 \pm 1.70(p=0.1)$ and from $-0.7 \pm 1.2$ to $-0.4 \pm 1.2(p=0.3)$ respectively from 2007 to 2016 . FEV1 $\mathrm{Z}$ score declined by an average of 0.17 per year of age and this was mirrored by an average decline in BMI Z scores of 0.07 for each year of advancing age. FEV1 decline was greater in patients who died compared to those who survived $(p=0.03)$. Of the factors postulated to influence lung function decline, there was no significant correlation between FEV1 at any age and age of diagnosis, sex, ethnicity, genotype, geographical location, pancreatic status, or Methicillinresistant S. aureus or Aspergillus spp. infection. Participants who were ever infected or colonised with $P$. Aeruginosa had consistently lower FEV1, however this difference only became significant at certain ages. On multiple stepwise regression analysis, only FEV1 at age 6 was found to be a significant independent predictor of mortality (adjusted odds ratio $(95 \% \mathrm{Cl}) 0.5(0.3-0.8) ; \mathrm{p}=$ 0.005).

Conclusion: Pulmonary function of children with cystic fibrosis improved non-significantly over the 10-year study period. FEV1 at age 6 was identified as an independent predictor for CF-related mortality. Early diagnosis and measurement of pulmonary function in young children with CF is essential to identify children at risk of poor outcomes. 


\section{LIST OF TABLES}

Table 1: Study participant characteristics

Table 2: Population change in lung function and BMI Z scores from 2007 to 2016.

Table 3: Bivariate analysis of potential predictors of mortality in South African children with CF

\section{LIST OF FIGURES}

Figure 1: Study participant flow diagram

Figure 2: Annual rates of decline in pulmonary function and body mass index

Figure 3: Mean change in FEV1 for survivors compared to those who died $(p=0.03)$

Figure 4: Correlation between BMI and FEV1 Z scores $(p<0,01)$

\section{ABBREVIATIONS}

ACT: Airway Clearance Therapy

AF: Aspergillus fumigatus

BMI: Body mass index

CF: Cystic fibrosis

CFTR: Cystic fibrosis transmembrane conductance regulator

FEF 25-75: Forced expiratory flow 25-75\%

FEV1: Forced expiratory volume in 1 second

FVC: Forced vital capacity

GLI: Global Lung Function Initiative

HREC: Human research ethics committee

LMIC: Low-middle income country

MRSA: Methicillin-resistant staphylococcus aureus

P. aeruginosa: Pseudomonas aeruginosa

PFT: Pulmonary function test

RCWMCH: Red Cross War Memorial Children's Hospital 


\section{ACKNOWLEDGEMENTS AND CONTRIBUTIONS}

I would like to thank my supervisors Prof Brenda Morrow and Dr Marco Zampoli for their academic input, guidance and support in the completion of my MMed in Paediatrics. 


\section{CHAPTER 1: INTRODUCTION AND LITERATURE REVIEW}

\subsection{BACKGROUND:}

Cystic fibrosis (CF) is a genetic disorder of autosomal recessive inheritance which is caused by mutations in the gene encoding for the cystic fibrosis transmembrane conductance regulator (CFTR)(1). It is a chronic progressive condition involving multiple organ systems which ultimately compromises their function (2). CF is one of the commonest inherited diseases in South Africa, affecting all population groups (3). Progressive pulmonary disease is the main predictor of morbidity and mortality in individuals with CF. CF lung disease is characterized by chronic endobronchial infection and inflammation which eventually causes airway obstruction and damage, ultimately leading to irreversible obstructive airway disease and respiratory failure $(4,5)$.

In addition to structural changes in the lungs, the progression of CF lung disease is predominantly described as deterioration in lung function over time (1) which has previously been noted to be predictable in developed countries (6).

Pulmonary function tests, including spirometry and lung clearance indices, serve as an objective and practical way to assess severity and survey the evolution of lung disease (6). The measurement of forced expiratory volume in 1 second (FEV1) by spirometry is particularly useful, as this measure is widely available even in resource-limited settings. A decline in FEV1 has been shown to be a predictor of hospitalization and is strongly associated with mortality. Thus, FEV1 can be used as an indicator for clinicians to change or intensify therapeutic regimens when treating patients with $\mathrm{CF}(2,6)$. 
Multiple factors associated with FEV1decline have been identified through studies conducted in developed countries. These include, amongst others: young age, female gender, high lung function, CFTR genotype, pancreatic insufficiency, diabetes mellitus, poor nutritional status, and infection with Pseudomonas aeruginosa and Burkholderia cepacia (7).

Children with CF in a resource-constrained country like South Africa however, face other hurdles such as poorer access to healthcare, and exposures such as the use of biomass fuels and an increased prevalence of different respiratory infections, including pulmonary tuberculosis (6). In many cases, FEV1 only becomes abnormal in the later stages of CF (2).

By early identification of factors that predict lung function deterioration, it is hoped that we might slow the progression of lung disease in patients with CF, and by doing so, improve survival and healthy longevity in people with CF.

However, studies examining decline in FEV1, and factors contributing to this decline in developing countries, are lacking. Currently studies assessing pulmonary function in patients with CF in South Africa have only been conducted in two centres, namely Red Cross War Memorial Children's Hospital (RCWMH) in Cape Town, and Steve Biko Academic Hospital in Pretoria $(3,6,8)$.

Morrow et al documented a significant improvement in lung function of children with CF managed at RCWMH in the Western Cape province of South Africa over the period from 1999 
to 2006. This is very encouraging, however the observed improvement was noted to occur at a time where medical care for patients with CF was rapidly evolving (6) and it is unclear whether these improvements have been sustained in the subsequent decade. One of the main objectives of CF management is to preserve lung health and slow the progression of lung disease, and this medical management is guided by research (1).

\subsection{LITERATURE REVIEW:}

1.2.1 AIMS AND OBJECTIVES:

The aims and objectives of this study are to:

1. Describe the modifiable and non-modifiable predictors of pulmonary function decline, in children with CF.

2. Identify areas where further research may be beneficial.

\subsubsection{SEARCH METHODS:}

An online search using the Pubmed Database was conducted. The following keywords were used to undertake 12 searches of the database:

Search \#1: Cystic fibrosis AND Pulmonary function tests AND South Africa

Search \#2: Cystic fibrosis AND Pulmonary function AND children AND ethnicity

Search \#3: Cystic fibrosis AND Pulmonary function AND children AND socio-economic status

Search \#4: Cystic fibrosis AND Pulmonary function AND children AND outcomes AND age at diagnosis

Search \#5: Cystic fibrosis AND Pulmonary function AND children AND pancreatic insufficiency Search \#6: Cystic fibrosis AND Pulmonary function AND children and MRSA 
Search \#7: Cystic fibrosis AND Pulmonary function AND children AND Methicillin-Resistant Staphylococcus Aureus

Search \#8: Cystic fibrosis AND Pulmonary function AND children AND Aspergillus Fumigatus

Search \#9: Cystic fibrosis AND Pulmonary function AND children AND Non-tuberculous Mycobacterium

Search \#10: Cystic fibrosis AND Pulmonary function AND children AND Pseudomonas

Search \#11: Cystic fibrosis AND Pulmonary Function AND children and BMI and Nutrition

Search \#12: Cystic fibrosis AND Pulmonary Function AND children AND gender and mortality Filters used were: Humans; abstract; free full text.

The most recent search was conducted on 09 March 2019. Titles and abstracts were reviewed to identify relevant publications. References of these publications were then explored, and relevant articles were extracted.

\subsubsection{INCLUSION CRITERIA}

All types of study design were considered for inclusion, however only those published in English were used. Studies involving both children up to 18 years old and adults were included if these categories were individually analysed and the study was deemed relevant. No limitation was placed on date of study, however more recent studies conducted in the last 10-15 years were prioritised.

\subsubsection{EXCLUSION CRITERIA}

Studies exclusively involving adults. 


\subsection{SEARCH RESULTS}

The initial search revealed 873 studies, of which 36 met inclusion criteria.

\subsubsection{DATA SYNTHESIS AND DISCUSSION \\ Non-modifiable factors:}

SEX:

The relationship between gender and the decline in pulmonary function demonstrated by a decrease in FEV1, is still unclear with conflicting results from different studies (1). Previous studies have reported a "gender gap" (1), suggesting that female sex is a risk factor for severe lung disease (9). A systematic review by Harun et al. found that adult females had a steeper decline in FEV1 \% predicted when compared to males (1). It has been postulated that estrogen upregulates airway mucus production, thereby impairing mucociliary clearance and resulting in poorer lung function in females (10). Other studies that have shown a steeper decline in FEV1 in females than males have attributed this to different degrees of physical activity (6). A study by Cory et al found that male patients had a slower decline in FEV1 and increased survival which in turn equates to milder disease in males than in females. (11)Similar pulmonary function for males and females at baseline was noted by Harun et al (1). In a South African study by Morrow et al, no difference in FEV 1 decline between male and female participants could be demonstrated (6). One retrospective observational study by Cogen et al which involved participants in the Early Pseudomonas Infection Control (EPIC) Observational Study showed that females had a steeper rate of decline in pulmonary function than males, although the participants in this study had relatively mild disease. Of note is that this study 
also showed that this steeper rate of decline was not due to earlier infection of female CF patients with Pseudomonas aeruginosa (PA) (10).

\section{GENOTYPE:}

It has proved very difficult to make a definitive genotype-phenotype correlation in patients with CF, specifically because the presentation, clinical evolution and prognosis for these patients is so varied. Delta F508 is the most common CF genetic mutation in Caucasian and mixed-race populations in South Africa, and it is associated with earlier presentation, pancreatic insufficiency and more severe lung disease (12). This was demonstrated in a Danish study by Johansen where significantly more patients homozygous for Delta F508 were symptomatic by 6 months of age, diagnosed at a younger age, required more pancreatic enzyme replacement therapy, and had poorer pulmonary function (13). A systematic review by Harun et al found that patients homozygous for the F508 mutation have a more rapid decline in pulmonary function compared to patients with other mutation types (1). This was corroborated in studies by Morrow et al and Corey et al which showed that Delta F508 homozygous CF patients had a much greater rate of decline in pulmonary function $(6,11)$. Morrow et al however also showed that baseline pulmonary function at 6 years of age was significantly lower in CF patients who were Delta F508 heterozygous, but suggested that pulmonary disease in this group of patients may thereafter become more stable than Delta $F$ 508 homozygous counterparts. The relationship between Delta F 508 mutation types and severity of lung disease still needs to be studied further in South Africa (6). Several studies have shown an association between CFTR mutation and pancreatic insufficiency (12), and thus most studies examining genotype-phenotype correlation were confounded by pancreatic status, specifically in the F508 deletion group (1). It is therefore still unclear as to 
whether rate of FEV1 decline \% predicted is influenced by pancreatic function or genotype (1).

\section{PANCREATIC INSUFFICIENCY}

Pancreatic insufficiency is a well-recognised gastrointestinal complication in patients with CF (1). Pancreatic status is associated with CFTR genotype, and is thus an intrinsic factor that cannot be treated, however new therapies are under investigation which are aimed at converting a "severe" CFTR mutation into a "mild" mutation where the CFTR is partially functional (14). Therefore, pancreatic insufficiency may, in future, rather become a modifiable factor. Corey et al's 1997 study showed that patients with pancreatic sufficiency had a slower rate of decline of FEV1 (11). This finding was corroborated in a systematic review by Harun et al which indicated that pancreatic insufficiency was associated with a steeper decline in FEV1 $\%$ predicted (1). Thus, studies that assess pulmonary function in patients with CF must take into account patients' pancreatic status which may vary between groups (14). It is well recognised that patients with pancreatic sufficiency have better nutritional status (14), whereas patients with pancreatic insufficiency have poorer nutritional status which causes poorer pulmonary function and lung growth, and ultimately faster decline in pulmonary function (1). An important study by Kerem et al controlled for other modifiable factors known to affect pulmonary function in patients with $\mathrm{CF}$, namely nutrition, infection with Pseudomonas aeruginosa, and CF related diabetes. By doing so, study researchers were able to prove that patients with pancreatic sufficiency have better pulmonary function independent of these modifiable factors (14). Unfortunately, there is a paucity of South African studies examining the relationship between pancreatic status and pulmonary function in patients with CF. 


\section{Modifiable factors:}

AGE AT DIAGNOSIS:

With the advent of newborn screening for CF, much debate regarding the benefits of early vs late diagnosis of CF, in terms of pulmonary function and outcome, has fuelled multiple studies looking at this topic, however, results are inconclusive. Morrow et al suggested that there may be crucial events that occur at a very young age which may dictate the severity of a patients CF pulmonary disease. Therefore, early diagnosis, improved methods of monitoring in young patients, and optimal timeous management, is essential to slow the rate of decline of lung function and thereby increase survival of patients with CF (6). Several international studies have shown no difference in the severity of lung disease between patients diagnosed with CF through newborn screening versus patients diagnosed later with symptoms of CF $(9$, 15, 16). Sanders et al noted that better outcomes in CF are not guaranteed by newborn screening, however early diagnosis through newborn screening does afford the opportunity for better care resulting in improved nutrition and cognitive function in patients with CF (9). A 10 year French retrospective study by Siret et al, despite finding no difference in lung function, did find that children with CF diagnosed through newborn screening experienced fewer delays in initiating pancreatic enzyme supplementation, fewer hospitalizations and had better Z scores for weight and height than non-screened patients with CF (15). Two international studies demonstrated improved lung function in patients diagnosed with CF at an earlier age. A retrospective cohort study by Slieker et al found that an early diagnosis of CF was associated with better pulmonary function after two decades of life despite the fact that younger siblings seemed to be colonised with Pseudomonas at an early age (17). In an Australian retrospective review of patients with late diagnosis of CF, Coffey et al found that 
patients with late diagnosis CF had more respiratory manifestations at the time of diagnosis which equated to worse health, as well as poorer growth and worse pulmonary health later on (18).

A local study by Morrow et al found that patients with CF diagnosed after 5 years of age had FEV1 values consistent with moderately severe lung disease (averaging $<55 \%$ predicted) compared to those diagnosed earlier who had FEV1 values consistent with mild lung disease (averaging $>75 \%$ predicted). Results of this study suggest that suboptimal management in early life potentially impacts negatively on early lung function (6).

\section{SOCIOECONOMIC STATUS (SES):}

A strong association between SES and PFT has been demonstrated in international studies from the United Kingdom and the USA, and the reasons for this association are multifactorial (19). Connections have been drawn between poorer SES and worse clinical outcomes in patients with CF (20). This may be partly explained by the fact that FEV1 has been shown to be affected by SES in cross sectional analyses (10), and we know that FEV1 not only accurately demonstrates the progression of CF lung disease, but can be used to predict mortality too (6). Low SES is associated with poorer nutrition and lung function as well as a significant two to three times higher mortality rate (19).

CF affects all South African population groups and is an important, progressive chronic disease in our country (6). In a developing country such as South Africa, children with CF face additional exposures such as biomass fuel exposure and increased community prevalence of respiratory infections, and may have poorer access to health care than children living in developed countries, all of which may impact on pulmonary function (6) . In two South African 
studies by Morrow et al, ethnic group was used as a substitute for SES, as black Africans and people of mixed ancestry tend to reside in in worse socio-economic environments than white South Africans, owing to historical inequities. Patients with CF that are of mixed ancestry have been found to have overall higher mortality (6). Interestingly, both studies suggest that poorer patients are becoming less disadvantaged, as no difference in pulmonary function or prognosis in different ethnic groups could be demonstrated $(3,6)$.

Patients with CF should adhere to somewhat complex treatment regimens in order to slow disease progression and reduce the chance of early mortality. These regimens often include inhaled therapies, such as bronchodilators and mucolytics, antibiotics, as well as airway clearance therapy (ACT). The impact of SES on adherence has been clearly demonstrated in many chronic diseases, but less so in CF. Most studies have investigated adherence to specific medication regimens in CF patients rather than $\mathrm{ACT}$, which is the most time-consuming aspect of the CF treatment regimen (21). A study conducted at the Children's of Alabama CF centre, which used Cockerham's Lifestyle theory which maintains that health behaviours are shaped by socio-economic conditions, demonstrated that a SES-adherence association does exist in CF, specifically for ACT. This study echoed previous study findings of an association between SES and pulmonary health by illustrating that better respiratory outcomes were associated with college education, income and the number of adults in each household. Analyses showed that college education was associated with medium adherence and medium lung function; high income is associated with high adherence, and that for every additional adult in a household, the likelihood of medium adherence is doubled, while the likelihood of high lung function is quadrupled. Therefore, the risk of worse respiratory outcomes due to poor adherence is higher in single adult households (21). 
Pulmonary function in healthy children has been shown to be adversely affected by exposure to second-hand smoke. However, previous studies which aimed to demonstrate the association between second- hand smoke exposure and poorer outcomes in children with CF have been inconsistent, which is thought to be largely due to the differences in power of the various studies to determine the negative effects of second-hand smoke exposure. A powerful study conducted in the US, using data collected by the US Cystic Fibrosis Twin and Sibling study and the Cystic Fibrosis Foundation Data registry, confirmed that poorer lung function was associated with a higher prevalence of environmental tobacco smoke exposure in patients with CF, particularly in those with low SES. This study also demonstrated that adjustment for second-hand smoke exposure significantly altered the relationship between SES and CF outcomes, indicating that the relationship between low SES and lower pulmonary function is largely related to the fact that children with CF with lower SES to second-hand smoke to a greater degree $(19,22)$. The same study also examined gene-environment interactions, and found that the CFTR gene which causes disease in CF, modifies the association between second-hand smoke and poor pulmonary outcomes in patients with CF. The delta F508 mutation on the CFTR gene causes complete loss of function, whereas some non-delta F508 mutations allow partial function of the CFTR gene. The pulmonary function of patients carrying at least one non-Delta F508 mutation was more greatly affected by secondhand smoke exposure than the delta F508 homozygous patients. Further studies involving patients who both homozygous and heterozygous for the delta F508 mutation are needed to explore the negative effects of second-hand smoke on pulmonary function of patients with CF (22). 


\section{NUTRITION:}

It is a widely-accepted fact that adequate nutrition in patients with CF is crucial for their quality of life and ultimately impacts on their survival. The relationship between malnutrition and progression of lung disease has been demonstrated in multiple studies from developed countries (23). Malnutrition in patients with CF is multifactorial, and results from poor absorption due to pancreatic insufficiency, anorexia and chronic suppurative lung disease which increases energy requirements. Besides negatively impacting lung growth, malnutrition can also reduce muscle mass which results in reduced force of contraction of the diaphragm and other respiratory muscles and impaired lung function. This, together with impaired immunity and antioxidant deficit due to malnutrition, makes malnourished children with CF particularly vulnerable to infection and pulmonary inflammation $(23,24)$.

The most accepted measurement to assess the nutritional status of patients with CF is the body mass index (BMI). A cross-sectional study performed in a CF centre in Brazil involving patients from 6 to 18 years showed that $\mathrm{BMI}$ on the $50^{\text {th }}$ percentile or more was associated with more desirable FEV1 of greater than or equal to $80 \%$ (23). Pedreira et al also demonstrated a significant correlation between BMI Z score and FEV1, as well as muscle mass and FEV 1 (25). Chaves et al (2009) also showed an association between BMI and pulmonary function, but cautioned that BMI does not describe body composition and should not be used alone to assess the nutritional status of patients with CF. In CF there is a disproportionate loss of lean muscle mass due to the body favouring protein degradation rather than protein synthesis to meet its energy requirements, thus reduced pulmonary function can result from malnutrition due to a change in body composition (26). Although body wasting has clearly been shown to be an independent predictor of mortality in patients with CF, there is a paucity of evidence regarding the association between stunting and mortality in CF patients. Previous 
studies suggesting that stunting was related to mortality did not adjust for confounding variables, however a case-control study by Vieni et al (2012) specifically adjusted statistical analysis for age, gender, genotype, pancreatic status and CF-related diabetes, BMI, Pseudomonas or Burkholderia cepacia colonisation and FEV1. This was the first study to show that stunting is an independent risk factor for mortality in CF patients, and that nutritional interventions for stunting alone, is justified (27).

Albumin is a powerful antioxidant necessary to maintain pulmonary glutathione levels. It has been found that some patients with CF have oxidatively modified albumin in their sputum, which may cause the albumin to lose its antioxidant properties (23). Albumin level has been related to the severity of pulmonary disease and prognosis in patients with CF (28). In a crosssectional study in Brazil by Forte et al (2012), patients with FEV1 $<80 \%$ had significantly different albumin levels, despite the albumin being within normal range (28). The relationship between low plasma albumin and greater morbidity and mortality in CF patients has been described. A study that examined a model used to predict life expectancy in patients with CF showed that plasma albumin levels could predict survival (23).

\section{INFECTIONS:}

Airway infection and the ensuing airway inflammation is responsible for up to $95 \%$ of morbidity and mortality in patients with CF. Both impaired mucociliary clearance and viscous airway secretions are factors which promote respiratory tract infections in patients with CF. These factors are ultimately the result of an absent or dysfunctional CFTR protein due to mutations in the CFTR gene (29). 


\section{-Aspergillus fumigatus}

Filamentous fungi are frequently cultured from respiratory secretions in patients with CF, but their clinical significance remains uncertain (30). The most common fungal microorganism isolated from CF airways is Aspergillus fumigatus (AF), with a prevalence reported between 16 and 58\% (31-34). In a study by Reece et al, AF colonisation was found to be most prevalent in in pre-adolescents and adolescents. There is currently no consensus on the treatment of asymptomatic AF colonisation, in light of the fact that AF does not usually cause invasive infections in patients with CF. Allergic bronchopulmonary aspergillosis, however, which may result from a hypersensitivity reaction to $A F$, has been proven to have a severe adverse influence on airway inflammation. The effect of AF on disease progression in patients with CF has been studied, but it remains unclear (29). An 8-year retrospective cohort study by Saunders et al (2016) concluded that AF colonization may be associated with worse pulmonary function (30). In a retrospective cohort study by de Vrankrijker et al (2011), it was noted that although AF colonization was more commonly found in patients with more significant lung disease, AF was not independently associated with worse lung function or a more rapid decline in lung function (35). A bidirectional relationship between AF colonisation and poor lung function has been postulated, and was demonstrated in the results of case control study by Noni et al (2015), in which the investigators concluded that whilst a lower FEV1 baseline is a risk factor for AF chronic colonization, AF itself may also cause a more rapid worsening of pulmonary function (36). Other studies, including a retrospective study by Reece et al conducted on data obtained from the Cystic Fibrosis Registry of Ireland (2013), have shown no causal relationship between AF colonization and worsening pulmonary function (29). This finding may be due to correction for confounders and baseline pulmonary function. 


\section{Pseudomonas aeruginosa:}

The most common bacterial organism in CF is Pseudomonas aeruginosa. In patients with CF, $P$. aeruginosa colonization is usually intermittent early on, however, if re-colonisation occurs, with failure of eradication, patients may become persistently colonised with $P$. aeruginosa, after which pulmonary function declines and mortality increases (29). A systematic review by Harun et al noted a significant association between chronic infection with $P$. aeruginosa and CF pulmonary disease progression in all studies that examined this outcome measure (1), however evidence to the contrary exists, for example a study by Amin et al found that $P$. aeruginosa was not associated with a decline in lung function (37). Kerem et al (2014) found the likelihood of severe lung disease was 2.4 times higher in patients with CF and chronic Pseudomonas infection (14). A South African Study by Pentz et al conducted at Steve Biko Academic Hospital in Pretoria (2014) also demonstrated that patients with CF with $P$. aeruginosa colonisation had a decline in pulmonary function (8). Similarly, this study showed that patients with CF who were colonised by $P$. aeruginosa had a greater rate of change in FEF 25-75 than those who were not colonised (8). Patients develop antibodies to Pseudomonas when they are colonised with the organism, and it is thought that this immune response plays a role in the lung damage in patients with CF. In a study by Winnie and Cowan (1991), patients with CF with chronic Pseudomonas infection had higher antibody levels and worse pulmonary function (38).

$P$. aeruginosa infection may be further subclassified into mucoid and non-mucoid types, the former being associated with more rapid decline in pulmonary function than non-mucoid $P$. aeruginosa infection. (1). In a study by Sanders et al, investigators found no association between FEV1 and $P$. aeruginosa infection in general, but there was a significant association between FEV1 and mucoid Pseudomonas (9). Besides the decline in lung function, $P$. 
aeruginosa colonisation also severely impairs growth and the quality of life of patients with CF (8).

Methicillin-resistant Staphylococcus aureus (MRSA):

First identified in 1960, Methicillin-Resistant Staphylococcus aureus (MRSA) general infection is increasing in the paediatric population, as is its isolation in the sputum of paediatric patients with CF (39). Despite this, there are still few studies assessing the impact of MRSA on pulmonary function in patients with CF. Results of studies are also conflicting, with some showing that MRSA does not impact on pulmonary function, and others indicating that MRSA is associated with deterioration of, and overall poorer, pulmonary function(40). Ren at al (2007) conducted a cross sectional study using data from the Epidemiologic Study of Cystic Fibrosis. They showed that patients with CF and MRSA infection had a lower mean FEV1 \% predicted than those with methicillin-sensitive Staphylococcus aureus (MSSA) (41). MRSA infection is known to be associated with more severe lung disease in patients with $\mathrm{CF}$, as well as a generally lower FEV1. Dasenbrook et al conducted a large 10-year Cohort study (2008) using the CF Foundation patient registry in North America which was able to perform an indepth analysis of the longitudinal effect of MRSA in CF. This study demonstrated that persistent infection with MRSA in patients with CF was associated with an increase in rate of pulmonary function decline of approximately 0,5 FEV1 \% predicted per year, compared to those without MRSA. Importantly, the results of this study also suggested that, after adjusting for confounding factors, persistent MRSA infection was responsible for a decline in pulmonary function (40).

Staphylococci possess toxins which damage cell membranes, as well as substances called invasins which assist with bacterial tissue invasion (40), however it is still unclear exactly how 
MRSA may worsen pulmonary function in patients with CF. It has been noted that children with CF more commonly have community-aquired strains of MRSA which have increased virulence when compared to nosocomial strains (40). The exact mechanism by which MRSA causes a decline in lung function may be established by further studies examining MRSA molecular epidemiology and clinical outcomes (40).

\subsection{STUDY RATIONALE:}

The purpose of this research is to outline the changes in lung function that occur over time in a paediatric and adolescent population with CF, attending the Red Cross War Memorial Children's Hospital (RCWMCH) CF Clinic (Cape Town, South Africa), and to investigate the factors that affect lung function decline. By doing so we hope to identify high risk patients in whom more aggressive treatment and modification of risk factors would be beneficial. This could also form the basis of further research, the results of which may positively impact on future management of children and adolescents attending the CF clinic at RCWMCH.

\subsection{ETHICAL CONSIDERATIONS:}

The study described in chapter 2 was a retrospective review of data retrospective review of data routinely collected as part of the approved CF

database (HREC 119/2011). Informed consent to record patient data in the registry was previously obtained from the parents/guardians of all potential participants.

The study population is a recognised vulnerable group, being children with a severe, chronic disease; however, considering the descriptive, non-interventional nature of the study and the 
use of anonymised data, this study was deemed to constitute minimal risk of research-related harm to the minor participants. The only foreseeable harm would arise from breach of confidentiality, and the following measure are in place to minimise this risk:

i. Patient identifiers were removed and replaced by a code.

ii. No potentially identifying or identifiable information will appear in any output arising from this research.

iii. Hard copies of data are stored in a locked filing cupboard.

iv. Electronic copies of data are saved in password protected files accessible only to the researchers.

Although the study held no potential benefit to participants, the generalizable knowledge which will contribute to better understanding and future management of children with $\mathrm{CF}$ in South Africa.

The study adhered to the provisions of the Declaration of Helsinki (2013) (42) and the 2015 South African National Department of Health's “Ethics in Health Research: Principles, Processes and Structures" ( $2^{\text {nd }}$ Edition) (43). The study was approved by the University of Cape Town's Faculty of Health Sciences Human Research Ethics Committee (HREC) (Rec Ref: 830/2017). 


\section{REFERENCES:}

1. Harun SN, Wainwright C, Klein K, Hennig S. A systematic review of studies examining the rate of lung function decline in patients with cystic fibrosis. Paediatric respiratory reviews. 2016;20:55-66.

2. Heinzmann-Filho JP, Pinto LA, Marostica PJ, Donadio MV. Variation in lung function is associated with worse clinical outcomes in cystic fibrosis. Jornal brasileiro de pneumologia : publicacao oficial da Sociedade Brasileira de Pneumologia e Tisilogia. 2015;41(6):509-15.

3. Morrow BM, Argent AC, Zar HJ, Westwood AT. Improvements in lung function of a pediatric cystic fibrosis population in a developing country. Jornal de pediatria. 2008;84(5):403-9.

4. Ren CL, Rosenfeld M, Mayer OH, Davis SD, Kloster M, Castile RG, et al. Analysis of the associations between lung function and clinical features in preschool children with cystic fibrosis. Pediatric pulmonology. 2012;47(6):574-81.

5. Morgan WJ, Wagener JS, Yegin A, Pasta DJ, Millar SJ, Konstan MW. Probability of treatment following acute decline in lung function in children with cystic fibrosis is related to baseline pulmonary function. The Journal of pediatrics. 2013;163(4):1152-7.e2.

6. Morrow BM, Argent AC, Distiller GB, Zar HJ, Westwood ATR. Rate of pulmonary function decline in South African children with cystic fibrosis. SAJCH. 2009;3:73-7.

7. Konstan MW, Morgan WJ, Butler SM, Pasta DJ, Craib ML, Silva SJ, et al. Risk factors for rate of decline in forced expiratory volume in one second in children and adolescents with cystic fibrosis. The Journal of pediatrics. 2007;151(2):134-9, 9.e1.

8. Pentz A, Becker P, Masekela R, Coetzee O, Green RJ. The impact of chronic pseudomonal infection on pulmonary function testing in individuals with cystic fibrosis in Pretoria, South Africa. South African medical journal = Suid-Afrikaanse tydskrif vir geneeskunde. 2014;104(3):191-4.

9. Sanders DB, Li Z, Laxova A, Rock MJ, Levy H, Collins J, et al. Risk factors for the progression of cystic fibrosis lung disease throughout childhood. Annals of the American Thoracic Society. 2014;11(1):63-72.

10. Cogen J, Emerson J, Sanders DB, Ren C, Schechter MS, Gibson RL, et al. Risk factors for lung function decline in a large cohort of young cystic fibrosis patients. Pediatric pulmonology. 2015;50(8):763-70.

11. Corey $M$, Edwards L, Levison $\mathrm{H}$, Knowles $\mathrm{M}$. Longitudinal analysis of pulmonary function decline in patients with cystic fibrosis. The Journal of pediatrics. 1997;131(6):809-14. 12. Schibler A, Bolt I, Gallati S, Schoni MH, Kraemer R. High morbidity and mortality in cystic fibrosis patients compound heterozygous for 3905insT and deltaF508. The European respiratory journal. 2001;17(6):1181-6.

13. Johansen HK, Nir M, Hoiby N, Koch C, Schwartz M. Severity of cystic fibrosis in patients homozygous and heterozygous for delta F508 mutation. Lancet (London, England). 1991;337(8742):631-4.

14. Kerem E, Viviani L, Zolin A, MacNeill S, Hatziagorou E, Ellemunter $H$, et al. Factors associated with FEV1 decline in cystic fibrosis: analysis of the ECFS patient registry. The European respiratory journal. 2014;43(1):125-33.

15. Siret D, Bretaudeau G, Branger B, Dabadie A, Dagorne M, David V, et al. Comparing the clinical evolution of cystic fibrosis screened neonatally to that of cystic fibrosis diagnosed from clinical symptoms: a 10-year retrospective study in a French region (Brittany). Pediatric pulmonology. 2003;35(5):342-9. 
16. Sims EJ, Clark A, McCormick J, Mehta G, Connett G, Mehta A. Cystic fibrosis diagnosed after 2 months of age leads to worse outcomes and requires more therapy. Pediatrics. 2007;119(1):19-28.

17. Slieker MG, van den Berg JM, Kouwenberg J, van Berkhout FT, Heijerman HG, van der Ent CK. Long-term effects of birth order and age at diagnosis in cystic fibrosis: a sibling cohort study. Pediatric pulmonology. 2010;45(6):601-7.

18. Coffey MJ, Whitaker V, Gentin N, Junek R, Shalhoub C, Nightingale S, et al. Differences in Outcomes between Early and Late Diagnosis of Cystic Fibrosis in the Newborn Screening Era. The Journal of pediatrics. 2017;181:137-45.e1.

19. Ong T, Schechter M, Yang J, Peng L, Emerson J, Gibson RL, et al. Socioeconomic Status, Smoke Exposure, and Health Outcomes in Young Children With Cystic Fibrosis. Pediatrics. 2017;139(2).

20. Taylor-Robinson DC, Smyth RL, Diggle PJ, Whitehead M. The effect of social deprivation on clinical outcomes and the use of treatments in the UK cystic fibrosis population: a longitudinal study. The Lancet Respiratory medicine. 2013;1(2):121-8.

21. Oates GR, Stepanikova I, Gamble S, Gutierrez HH, Harris WT. Adherence to airway clearance therapy in pediatric cystic fibrosis: Socioeconomic factors and respiratory outcomes. Pediatric pulmonology. 2015;50(12):1244-52.

22. Collaco JM, Vanscoy L, Bremer L, McDougal K, Blackman SM, Bowers A, et al. Interactions between secondhand smoke and genes that affect cystic fibrosis lung disease. Jama. 2008;299(4):417-24.

23. Souza dos Santos Simon MI, Drehmer $M$, de Abreu ESFA, Hoffmann A, Druck Ricachinewsky $C$, de Fonseca Andrade Procianoy $E$, et al. Association of nutritional status, plasma, albumin levels and pulmonary function in cystic fibrosis. Nutricion hospitalaria. 2011;26(6):1322-7.

24. Hauschild DB, Rosa AF, Ventura JC, Barbosa E, Moreira EAM, Ludwig Neto $N$, et al. ASSOCIATION OF NUTRITIONAL STATUS WITH LUNG FUNCTION AND MORBIDITY IN CHILDREN AND ADOLESCENTS WITH CYSTIC FIBROSIS: A 36-MONTH COHORT STUDY. Revista paulista de pediatria : orgao oficial da Sociedade de Pediatria de Sao Paulo. 2018;36(1):8.

25. Pedreira CC, Robert RG, Dalton V, Oliver MR, Carlin JB, Robinson P, et al. Association of body composition and lung function in children with cystic fibrosis. Pediatric pulmonology. 2005;39(3):276-80.

26. Chaves CR, Britto JA, Oliveira CQ, Gomes MM, Cunha AL. Association between nutritional status measurements and pulmonary function in children and adolescents with cystic fibrosis. Jornal brasileiro de pneumologia : publicacao oficial da Sociedade Brasileira de Pneumologia e Tisilogia. 2009;35(5):409-14.

27. Vieni G, Faraci S, Collura M, Lombardo M, Traverso G, Cristadoro S, et al. Stunting is an independent predictor of mortality in patients with cystic fibrosis. Clinical nutrition (Edinburgh, Scotland). 2013;32(3):382-5.

28. Forte GC, Pereira JS, Drehmer M, Simon MI. Anthropometric and dietary intake indicators as predictors of pulmonary function in cystic fibrosis patients. Jornal brasileiro de pneumologia : publicacao oficial da Sociedade Brasileira de Pneumologia e Tisilogia. 2012;38(4):470-6.

29. Reece E, Segurado R, Jackson A, McClean S, Renwick J, Greally P. Co-colonisation with Aspergillus fumigatus and Pseudomonas aeruginosa is associated with poorer health in cystic fibrosis patients: an Irish registry analysis. BMC pulmonary medicine. 2017;17(1):70. 
30. Saunders RV, Modha DE, Claydon A, Gaillard EA. Chronic Aspergillus fumigatus colonization of the pediatric cystic fibrosis airway is common and may be associated with a more rapid decline in lung function. Medical mycology. 2016;54(5):537-43.

31. Skov M, McKay K, Koch C, Cooper PJ. Prevalence of allergic bronchopulmonary aspergillosis in cystic fibrosis in an area with a high frequency of atopy. Respiratory medicine. 2005;99(7):887-93.

32. Valenza G, Tappe D, Turnwald D, Frosch M, Konig C, Hebestreit H, et al. Prevalence and antimicrobial susceptibility of microorganisms isolated from sputa of patients with cystic fibrosis. Journal of cystic fibrosis : official journal of the European Cystic Fibrosis Society. 2008;7(2):123-7.

33. Amin R, Dupuis A, Aaron SD, Ratjen F. The effect of chronic infection with Aspergillus fumigatus on lung function and hospitalization in patients with cystic fibrosis. Chest. 2010;137(1):171-6.

34. Stevens DA, Moss RB, Kurup VP, Knutsen AP, Greenberger P, Judson MA, et al. Allergic bronchopulmonary aspergillosis in cystic fibrosis--state of the art: Cystic Fibrosis Foundation Consensus Conference. Clinical infectious diseases : an official publication of the Infectious Diseases Society of America. 2003;37 Suppl 3:S225-64.

35. de Vrankrijker AM, van der Ent CK, van Berkhout FT, Stellato RK, Willems RJ, Bonten $\mathrm{MJ}$, et al. Aspergillus fumigatus colonization in cystic fibrosis: implications for lung function? Clinical microbiology and infection : the official publication of the European Society of Clinical Microbiology and Infectious Diseases. 2011;17(9):1381-6.

36. Noni M, Katelari A, Dimopoulos G, Doudounakis SE, Tzoumaka-Bakoula C, Spoulou V. Aspergillus fumigatus chronic colonization and lung function decline in cystic fibrosis may have a two-way relationship. European journal of clinical microbiology \& infectious diseases : official publication of the European Society of Clinical Microbiology. 2015;34(11):2235-41.

37. Amin R, Lam M, Dupuis A, Ratjen F. The effect of early Pseudomonas aeruginosa treatment on lung function in pediatric cystic fibrosis. Pediatric pulmonology. 2011;46(6):5548.

38. Winnie GB, Cowan RG. Respiratory tract colonization with Pseudomonas aeruginosa in cystic fibrosis: correlations between anti-Pseudomonas aeruginosa antibody levels and pulmonary function. Pediatric pulmonology. 1991;10(2):92-100.

39. Miall LS, McGinley NT, Brownlee KG, Conway SP. Methicillin resistant Staphylococcus aureus (MRSA) infection in cystic fibrosis. Archives of disease in childhood. 2001;84(2):160-2. 40. Dasenbrook EC, Merlo CA, Diener-West M, Lechtzin N, Boyle MP. Persistent methicillin-resistant Staphylococcus aureus and rate of FEV1 decline in cystic fibrosis. American journal of respiratory and critical care medicine. 2008;178(8):814-21.

41. Ren CL, Morgan WJ, Konstan MW, Schechter MS, Wagener JS, Fisher KA, et al. Presence of methicillin resistant Staphylococcus aureus in respiratory cultures from cystic fibrosis patients is associated with lower lung function. Pediatric pulmonology. 2007;42(6):513-8.

42. World Medical Association Declaration of Helsinki: ethical principles for medical research involving human subjects. Jama. 2013;310(20):2191-4. 
TITLE PAGE:

Title: LUNG FUNCTION DETERMINANTS AND MORTALITY OF CHILDREN AND ADOLESCENTS WITH CYSTIC FIBROSIS IN SOUTH AFRICA 2007-2016

Author names and affiliations: Vandenbroucke $\mathrm{NJ}^{1,2}$, Zampoli $\mathrm{M}^{1,2}$, Morrow BM ${ }^{1}$

1. Department of Paediatrics and Child Health, University of Cape Town

2. Red Cross War Memorial Children's Hospital

Corresponding author: Professor Brenda Morrow

Mailing Address:

$5^{\text {th }}$ Floor ICH Building

Red Cross War Memorial Children's Hospital

Klipfontein Rd, Rondebosch

7708

Cape Town, South Africa

Email: Brenda.Morrow@uct.ac.za

Tel: $\quad$ +27(21) 6585967

Keywords: cystic fibrosis; pulmonary function; outcomes 


\section{Abbreviations}

\section{AF: Aspergillus fumigatus}

BMI: Body mass index

CF: Cystic fibrosis

CFTR: Cystic fibrosis transmembrane conductance regulator

FEF 25-75: Forced expiratory flow $25-75 \%$

FEV1: Forced expiratory volume in 1 second

FVC: Forced vital capacity

GLI: Global Lung Function Initiative

HREC: Human research ethics committee

LMIC: Low-middle income country

MRSA: Methicillin-resistant staphylococcus aureus

P. aeruginosa: Pseudomonas aeruginosa

PFT: Pulmonary function test

RCWMCH: Red Cross War Memorial Children's Hospital 


\title{
ABSTRACT:
}

\section{LUNG FUNCTION DETERMINANTS AND MORTALITY OF CHILDREN AND ADOLESCENTS WITH CYSTIC FIBROSIS IN SOUTH AFRICA 2007-2016}

\author{
Authors: Natalie Vandenbroucke; Marco Zampoli; Brenda Morrow
}

Objectives: Cystic fibrosis (CF) is one of the commonest inherited disorders in South Africa, affecting all population groups. Progressive pulmonary disease with declining forced expiratory volume in one second (FEV1) is the main predictor of morbidity and mortality in individuals with CF. This study aimed to describe the change in lung function, nutritional status and mortality of children and adolescents with CF, attending the Red Cross War Memorial Children's Hospital (RCWMCH) CF Clinic and to identify factors associated with poor pulmonary function outcomes and mortality.

Methods: A retrospective study was conducted of the clinical records and annual pulmonary function tests, with matched body mass index (BMI), of children between 5 and 18 completed years of age attending the RCWMCH CF clinic in Cape Town, South Africa, between January 2007 and December 2016.

Results: A total of 143 study participants (51.4\% male; median age at diagnosis 5.5 months) were included. Population mean FEV1 and body mass index (BMI) Z scores improved from $-2.5 \pm 1.70$ to $-1.9 \pm 1.70(p=0.1)$ and from $-0.7 \pm 1.2$ to $-0.4 \pm 1.2(p=0.3)$ respectively from 2007 to 2016 . FEV $1 \mathrm{Z}$ score declined by an average of 0.17 per year of age and this was mirrored by an average decline in BMI Z scores of 0.07 for each year of advancing age. FEV1 decline was greater in patients who died compared to those who survived $(p=0.03)$. Of the factors postulated to influence lung function decline, there was no significant correlation between FEV1 at any age and age of diagnosis, sex, ethnicity, genotype, geographical location, pancreatic status, or Methicillinresistant S. aureus or Aspergillus spp. infection. Participants who were ever infected or colonised with $P$. Aeruginosa had consistently lower FEV1, however this difference only became significant at certain ages. On multiple stepwise regression analysis, only FEV1 at age 6 was found to be a significant independent predictor of mortality (adjusted odds ratio $(95 \% \mathrm{Cl}) 0.5(0.3-0.8) ; p=$ 0.005).

Conclusion: Pulmonary function of children with cystic fibrosis improved non-significantly over the 10-year study period. FEV1 at age 6 was identified as an independent predictor for CF-related mortality. Early diagnosis and measurement of pulmonary function in young children with CF is essential to identify children at risk of poor outcomes. 


\section{INTRODUCTION:}

Cystic fibrosis (CF) is a genetic disorder of autosomal recessive inheritance (1) which is one of the commonest inherited disorders in South Africa, affecting all population groups (2). It is caused by a mutation in the gene encoding for the cystic fibrosis transmembrane conductance regulator (CFTR) protein (1), resulting in chronic progressive multisystem disease (3). The pathological basis of CF lung disease is chronic endobronchial infection and inflammation which gradually causes airway obstruction and damage ultimately resulting in irreversible obstructive lung disease and respiratory failure $(4,5)$. Lung disease is the strongest predictor of morbidity and mortality in patients with CF (6). An objective way of measuring the progression of CF lung disease is using pulmonary function tests (PFT) (7). Forced expiratory volume in 1 second (FEV1) is the most widely used measurement to guide clinical management of patients with CF as it has been shown to be a predictor of hospitalisation and is strongly associated with mortality $(3,7)$.

Numerous factors associated with FEV1 decline have been identified through studies conducted in high income countries (8). These factors can be divided into non-modifiable and modifiable groups. Non-modifiable factors include sex, genotype, and pancreatic sufficiency (1). The relationship between sex and pulmonary function decline is still unclear, with international studies demonstrating that female sex is associated with steeper FEV1 decline $(1,9,10)$, however in the only South African study examining the rate of pulmonary function decline in children with CF, no gender-related difference in FEV1 decline could be demonstrated (7). A definitive genotype-phenotype correlation in patients with CF is difficult, because the presentation, clinical evolution and prognosis for these patients is varied (11). 
Pancreatic insufficiency has been associated with a steeper decline in FEV1 $(1,10,12)$, however there is a paucity of South African studies examining this relationship.

Modifiable factors influencing FEV1 include age at CF diagnosis, socioeconomic status, nutrition and infections. The advent of newborn screening in high income countries has contributed to earlier diagnosis and improved outcomes $(13-15),(16,17)$. In a SA study by Morrow et al, children diagnosed with CF after 5 years of age had worse pulmonary function compared to those diagnosed before 5 years age (7). There is thus compelling evidence that early diagnosis and optimal timeous management is essential to improve pulmonary function outcomes and survival in patients with CF.

South Africa is a low-middle income country (LMIC) with high unemployment and extreme wealth and socioeconomic inequality. Connections have been drawn between poorer socioeconomic status and worse clinical outcomes in patients with CF (18), both in terms of lung function and a higher mortality rate (19). This is likely due to the fact that low socioeconomic status is associated with poorer nutrition (19), greater exposure to second-hand smoke (19, 20), and poorer adherence to both medical and airway clearance therapies (21).

Airway infection and the ensuing inflammation is responsible of up to $95 \%$ of morbidity and mortality in patients with CF (21) and Pseudomonas aeruginosa (P.aeruginosa) is the most common bacterial organism in CF (22). Persistent colonisation by $P$. aeruginosa after failure of eradication leads to a faster decline in pulmonary function and an increase in mortality, including in SA (7) (22) (23). 
Studies examining factors associated with pulmonary function decline in LMICs are lacking.

This study aimed to describe the change in lung function and mortality of children and adolescents with CF, attending the RCWMCH CF Clinic (Cape Town, South Africa) over the 10year period between January 2007 and December 2016. We further aimed to identify factors associated with poor pulmonary function outcomes in which more aggressive treatment and modification of risk factors may be beneficial.

\section{METHODS}

Study design and setting

A retrospective study of the clinical records and pulmonary function tests of children between 5 and 18 completed years of age attending the Red Cross War Memorial Children's Hospital (RCWMCH) CF clinic between January 2007 and December 2016 was conducted. This study was approved by the University of Cape Town Human Research Ethics Committee (HREC Ref 830/2017).

$\mathrm{RCWMCH}$ is a tertiary paediatric referral hospital situated in the Western Cape province of South Africa. Multidisciplinary CF care, according to SA guidelines (24), and access to essential CF medications is provided either free for poor families or through health care insurance in families who can afford this. Newborn screening for CF is not performed in South Africa and CF diagnosis is predominantly symptom-based. A significant number of patients at RCWMCH come from marginalised communities with poor socio-economic circumstances. 


\section{Study participant selection}

Eligible participants were identified by reviewing the RCWMH CF clinic database and medical records of patients attending the CF clinic between January 2007 and December 2016. Only children between 5 and 18 completed years of age with a confirmed diagnosis of CF were included. The diagnosis of CF in participants was based SA consensus guidelines (24) which includes either two positive sweat tests (sweat chloride $>60 \mathrm{mmol} / \mathrm{L}$ ) and clinical features compatible with CF disease and/or identification of two pathogenic CFTR variants. Children less than 5 years of age were excluded as young children are not reliably able to perform spirometry.

\section{Clinical data and outcome measures}

Participants were only included if they had performed at least two pulmonary function tests, one year apart, during the period of January 2007 to December 2016. The pre-bronchodilator PFT, weight and height measured on or closest to the participant's birthday was selected. If participants were unwell on this clinic visit, the next closest PFT conducted during a period of wellness, was utilised.

Data extracted from the CF clinic database and medical records included: date of birth, gender, CF genotype, age of CF diagnosis, mortality and age of death, ethnicity, presence of P.aeruginosa, Methicillin-resistant Staphylococcus Aureus (MRSA), aspergillus infection, age of first P.aeruginosa infection and P.aeruginosa colonisation, body mass index (BMI) at the time of PFT measurement, pancreatic sufficiency, and geographical location of habitation.

The following baseline PFT parameters were used for analysis: FEV1, Forced vital capacity (FVC, and average expiratory flow between 25 and 75\% of FVC (FEF25-75/ MEF). The percentage predicted for age, gender, height and ethnic group was used for analysis, along 
with the all-age (3-95 years), multi-ethnic Global Lung Function Initiative (GLI) spirometry equations (Z-scores), according to norm-referenced data (25).

\section{Statistical analysis}

For descriptive statistics, data were tested for normality using the Shapiro-Wilks W test, and presented as means (standard deviation) or median (interquartile range) and $\mathrm{n}(\%)$, according to distribution. Changes in population characteristics and annual PFT between 2007 and 2016 were analysed using repeated measures ANOVA with post-hoc-t-tests for dependant variables/Wilcoxin matched-pairs tests and t-tests for independent variables/Mann-Whitney $\mathrm{U}$ and chi-square tests, according to data distribution. Multivariate regression analyses will be used to assess the main effects on the changes in PFT variables. Longitudinal data was analysed using mixed model regression analysis (10). Repeated measures between- and within group ANOVAs will be conducted to determine changes in PFT with advancing age (from 5-18 years of age); and to determine the main effect variables (e.g. pancreatic sufficiency, ethnicity/genotype, infection status, and sex). Mortality (number of deaths) per annum will be recorded and plotted. Statistica version 13 (StatSoft, USA) was used for data analysis and a significant level of $p<0.05$ will be chosen, with Bonferonni correction where appropriate.

\section{RESULTS}

A total of 143 study participants were identified from the RCWMCH CF Clinic database. Of these, 107 participants $(51,4 \%$ male) were included in this study, the majority (55\%) homozygous for the p.Phe508del mutation and pancreatic insufficient (79\%) (Figure 1 table 1). Of these 107 participants, one was lost to follow up, 14 (15\%) patients died during the study period and $35(37,5 \%)$ patients were transferred to other facilities or healthcare providers for ongoing medical care. 


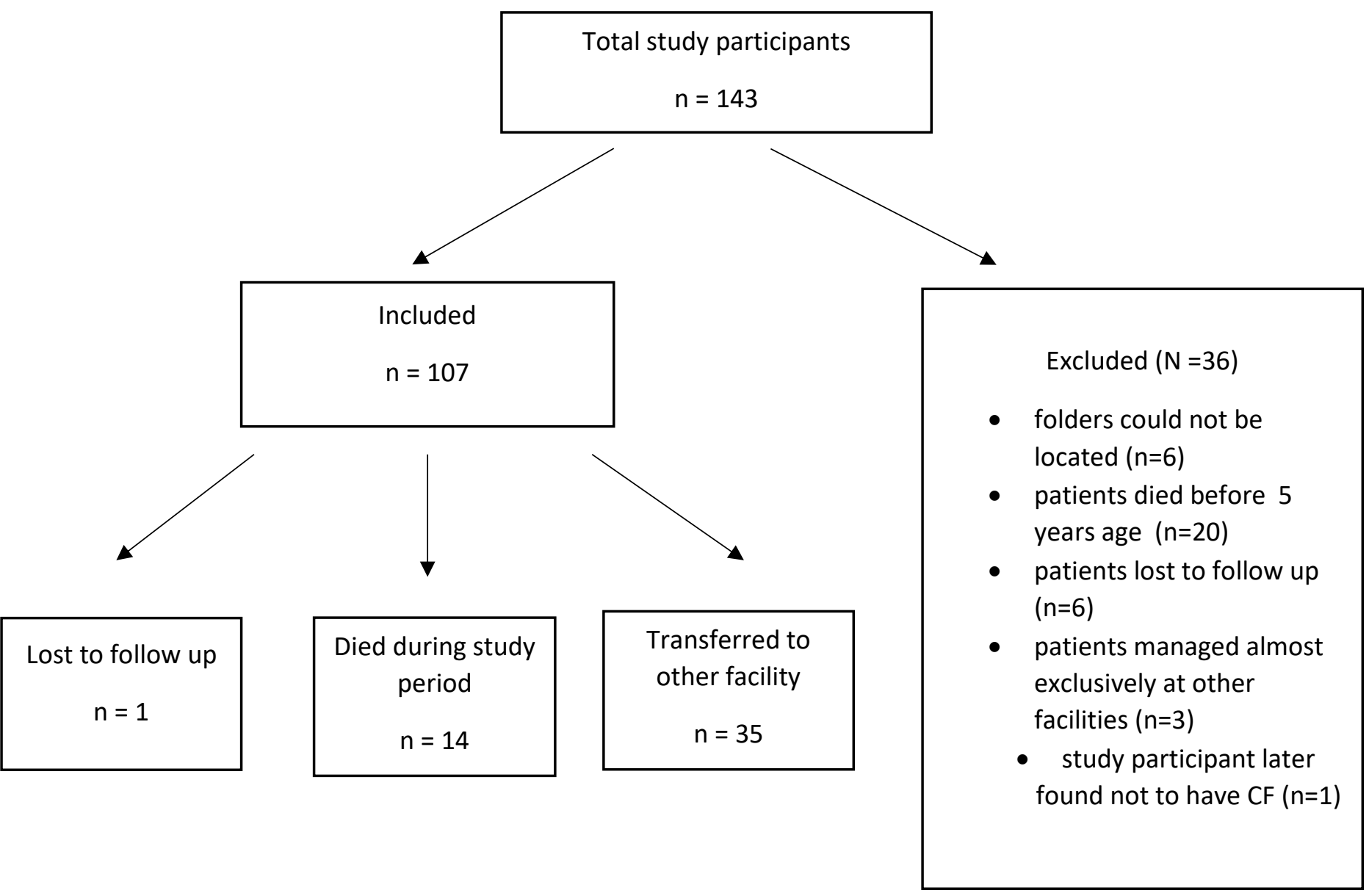

Figure 1: Study participant flow diagram. 
Table 1: Study participant characteristics

\begin{tabular}{|c|c|}
\hline Age at diagnosis (months) & $5,5(2,00-26,00)$ \\
\hline Male gender & $55(51,4)$ \\
\hline Sweat chloride (mmol/l) & $104(90-113)$ \\
\hline \multicolumn{2}{|l|}{ Ethnicity } \\
\hline White & $62(57,9)$ \\
\hline Black African & $6(5,6)$ \\
\hline Mixed ancestry & $38(35,5)$ \\
\hline Asian & $1(0,9)$ \\
\hline \multicolumn{2}{|l|}{ Genotype category } \\
\hline p.Phe508del homozygous & $55(51,4)$ \\
\hline p.Phe508del heterozygous & $29(27,1)$ \\
\hline Other & $18(16,8)$ \\
\hline Unknown & $5(4,7)$ \\
\hline \multicolumn{2}{|l|}{ Geographical area of residence } \\
\hline Greater Cape Town Metropole $(<100 \mathrm{~km})$ & $67(62,6)$ \\
\hline Western Cape (>100km from Cape Town) & $24(22,4)$ \\
\hline Other & $16(15)$ \\
\hline \multicolumn{2}{|l|}{ Pulmonary infections } \\
\hline Age at first PA years $(n=80)$ & $7,50(3,00-13,00)$ \\
\hline Age at PA colonisation (mean \pm SD) years $(n=29)$ & $10,2 \pm 4,85$ \\
\hline Ever Aspergillus fumigatus. & $43(40,2)$ \\
\hline MRSA & $10(9,3)$ \\
\hline Ever non-tuberculous mycobacteria & $9(8,4)$ \\
\hline \multicolumn{2}{|l|}{ Outcome } \\
\hline Died during study period & $14(13,1)$ \\
\hline Lost to followup & $1(0,9)$ \\
\hline Transferred & $35(32,7)$ \\
\hline
\end{tabular}

Continuous data are presented as median (IQR), unless otherwise stated. Categorical data are $n(\%)$; MRSA: Methicillin Resistant Staphylococcus Aureus; PA: Pseudomonas aeruginosa 
Change in population lung function and average annual rates of change:

There was an overall improvement in population lung function and BMI during the study period, as defined by FEV1, FVC and FEF 25-75, however this change was not significant. (Table 2).

Table 2: Population change in lung function and BMI Z scores from 2007 to 2016.

\begin{tabular}{|l|c|c|c|}
\hline & $\mathbf{2 0 0 7}$ & $\mathbf{2 0 1 6}$ & $\mathbf{p}$ \\
\hline FEV1 Z score & $-2,48 \pm 1,70$ & $-1,89 \pm 1,69$ & 0,1 \\
\hline FVC Z score & $-1,95 \pm 1,62$ & $-1,47 \pm 1,80$ & 0,2 \\
\hline FEF 25-75 Z score & $-2,43 \pm 1,84$ & $-1,91 \pm 1,41$ & 0,1 \\
\hline BMI Z score & $-0,74 \pm 1,22$ & $-0,43 \pm 1,19$ & 0,3 \\
\hline
\end{tabular}

Data are mean \pm SD. FEV1: forced expiratory volume in one second; FVC: forced vital capacity; FEF25-75: Forced expiratory flow between $25 \%-75 \%$ of the forced vital capacity; BMI: body mass index.

FEV1, FVC and FEF 25-75 Z scores all declined steadily with advancing age in our study population, with an estimated average decline of 0,$17 ; 0,12$; and 0,19 respectively per year of age (Figure 2). The decline in pulmonary function with age was mirrored by an estimated decline in BMI Z scores of 0,07 for each year of advancing age (Figure 2). 


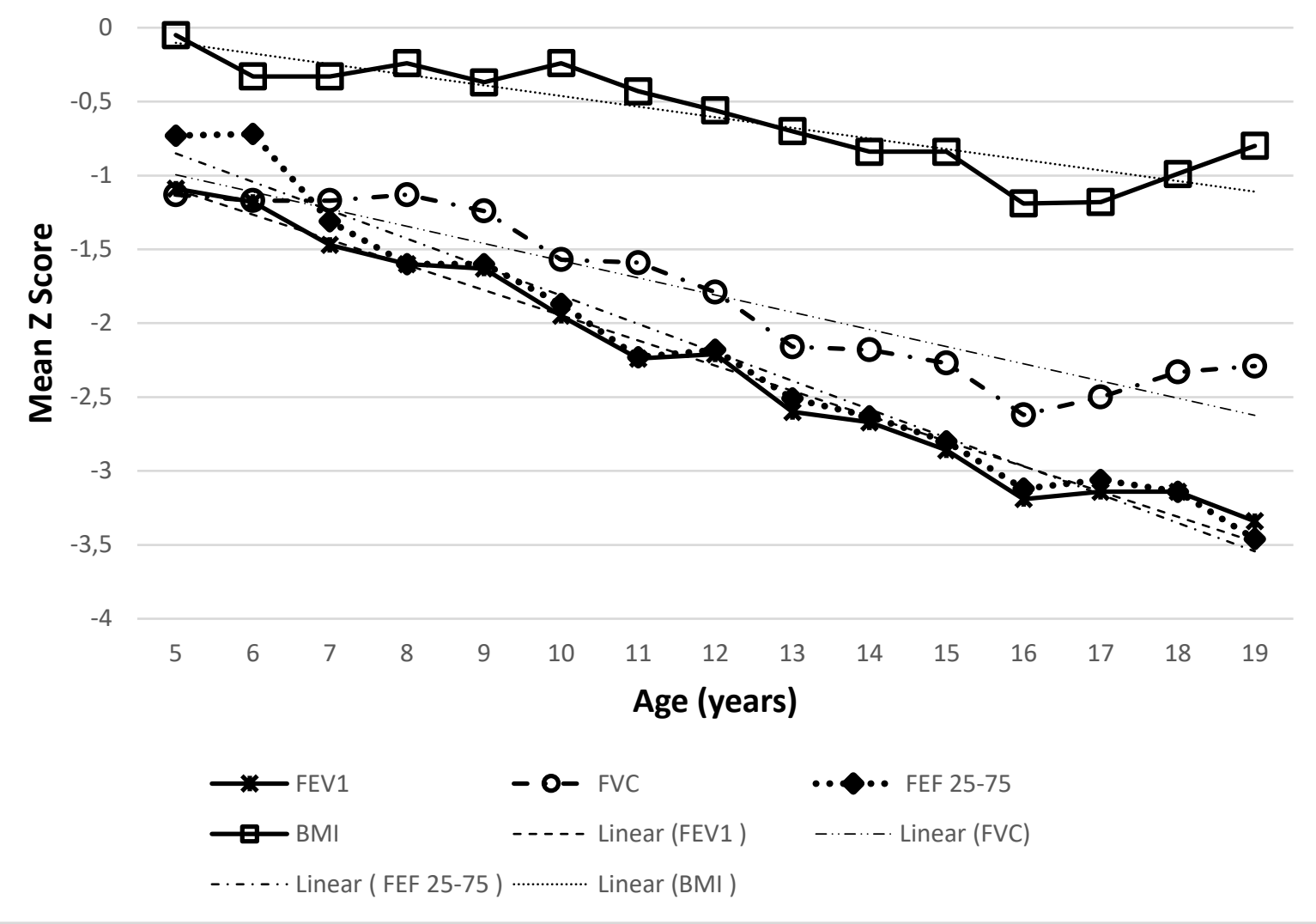

Figure 2: Annual rates of decline in pulmonary function and body mass index (BMI).

FEV1 was generally lower in patients who survived compared to those who died (current effect Anova $F(13,91)=1,99 ; p=0.03)$, however the mean annual rate of FEV1 decline was similar: $0.16 \pm 0.61$ in those who died vs $0.14 \pm 0.25$ in survivors ( $p=0.9$ ) (Figure 3 ). 


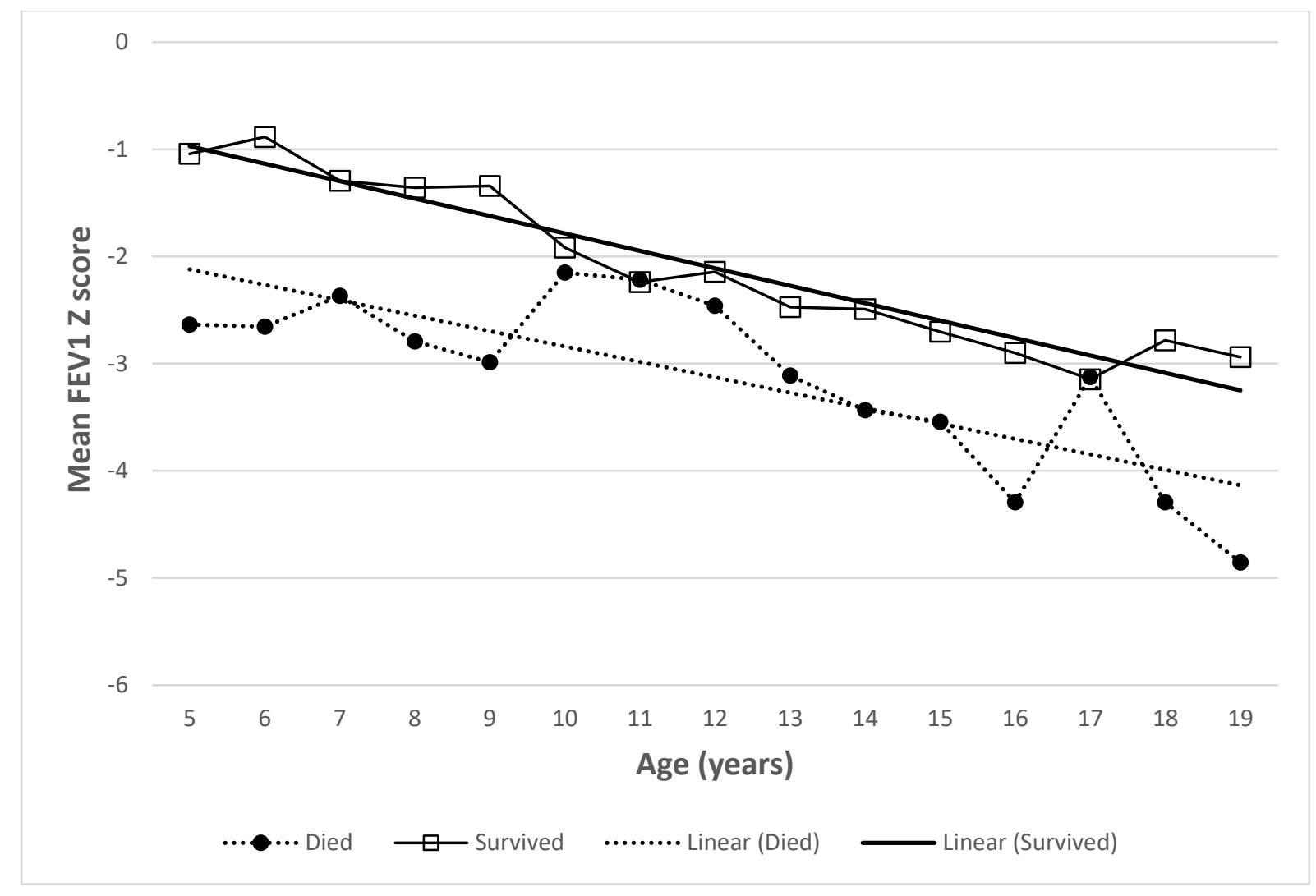

Figure 3: Mean change in FEV1 for survivors compared to those who died $(p=0.03)$

\section{Determinants of lung function:}

The median age at diagnosis was 5.5 months (IQR 2.00-26.00). There was no significant correlation between age of diagnosis and FEV1 Z scores at any age. There were no statistically significant differences between FEV1 between male and female participants at any given age; and the pattern of change was also similar over time (Anova current effect $F(13,91)=1,39$; $p=0,2)$. Similarly, there were no significant effects of ethnicity, genotype, geographical location, pancreatic status, or MRSA or Aspergillus infection on FEV1 at any age $(p>0.05)$. Whilst FEV1 in patients that had ever been infected with $P$. aeruginosa was consistently lower than FEV1 in patients who had never been infected with $P$. aeruginosa, the difference only became significant at age $7(p=0,02), 12(p=0,04)$ and $14(p=0,02)$ years of age. Similarly, 
patients who were colonised with $P$. aeruginosa had consistently lower FEV1 values than those who were not colonised, however this difference was only significant at age $6(p=0,03)$, $14(p=0,04)$ and $19(p=0,02)$ years of age. There was a significant correlation between BMI and FEV1 $Z$ scores $(R=0,92 ; p<0,01)$ (Figure 4). Age at first $P$. aeruginosa infection was associated with poor FEV1 at age 6; there were no other potential predictors of poor FEV1 at age 6 on bivariate analysis (Table 3).

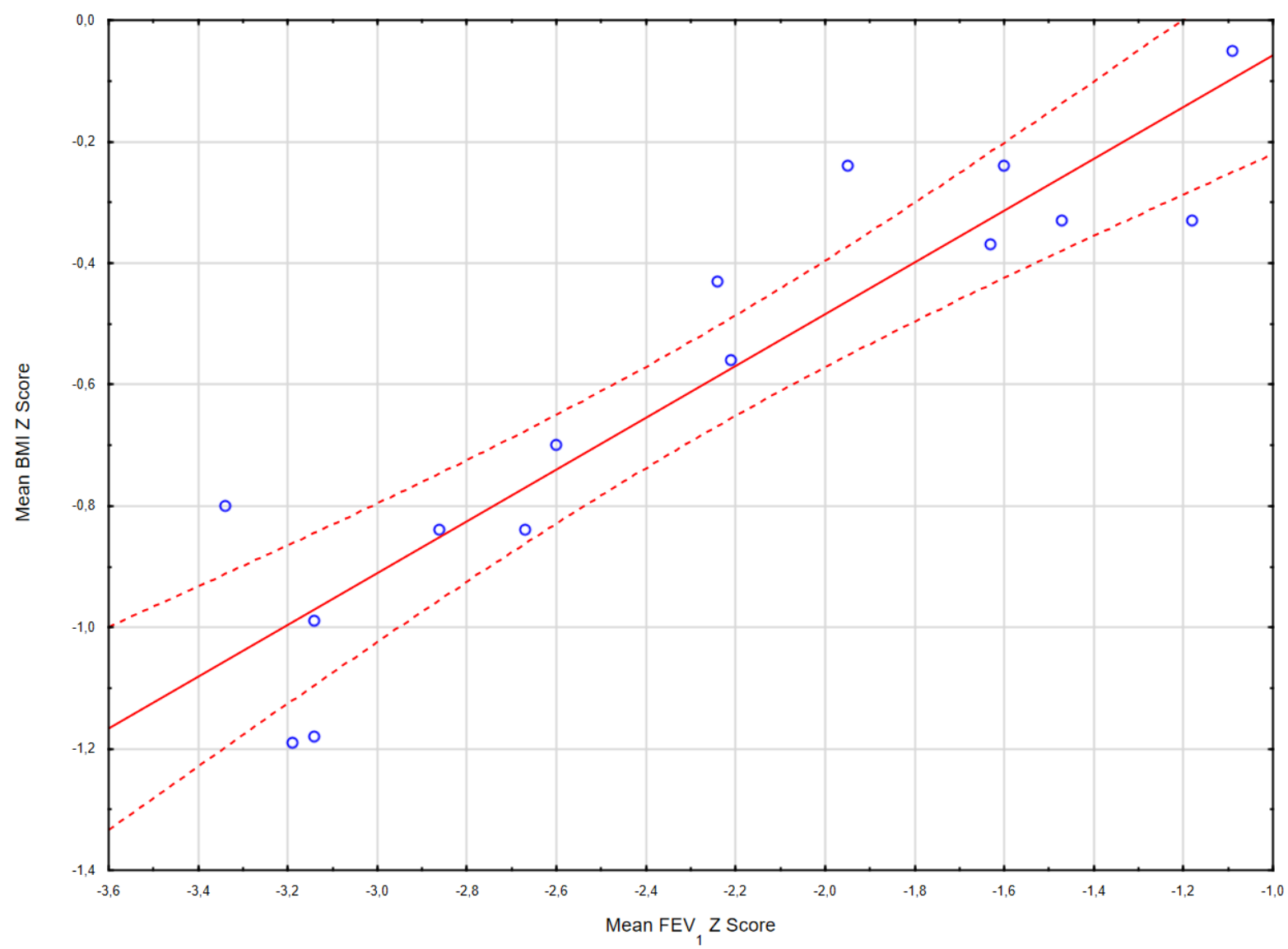

Figure 4: Correlation between BMI and FEV1 Z scores $(p<0,01)$

Only FEV1 at age 6 and $P$. aeruginosa colonisation were significant predictors of mortality on bivariate analysis (Table 4). On entering these variables into a stepwise multiple logistic 
regression, only FEV1 at age 6 remained a significant independent predictor of mortality in children with CF (adjusted odds ratio (95\% confidence interval) $0,5(0,31-0,81) ; p=0,005)$.

Table 3: Bivariate analysis of potential predictors of mortality in South African children with CF:

\begin{tabular}{|c|c|c|c|}
\hline & $\begin{array}{c}\text { Died } \\
N=14\end{array}$ & $\begin{array}{l}\text { Alive } \\
\mathrm{N}=93\end{array}$ & p-value \\
\hline Male sex & $9(64,3)$ & $46(49,5)$ & 0,5 \\
\hline PI & $12(85,7)$ & $73(78,5)$ & 0,8 \\
\hline Age at diagnosis & $6(3-37)$ & $5(1-24)$ & 0,5 \\
\hline Ever PA & $13(92,9)$ & $68(73,1)$ & 0,2 \\
\hline PA colonised & $8(57,1)$ & $21(22,6)$ & 0,009 \\
\hline Age at PA & $6(3-8)$ & $8(2-13)$ & 0,6 \\
\hline Age (y) PA colonised & $9(4-12,5)$ & $11(8-15)$ & 0,3 \\
\hline FEV1 Z score age 6 (mean \pm SD) & $-2,65 \pm 2,54$ & $-0,88 \pm 1,37$ & 0,003 \\
\hline BMI Z score age 6 (mean \pm SD) & $-0,66 \pm 1,20$ & $-0,27 \pm 1,90$ & 0,5 \\
\hline Ever MRSA & $1(7,1)$ & $9(9,7)$ & 0,9 \\
\hline \multicolumn{4}{|l|}{ GENOTYPE } \\
\hline p.Phe508del homozygous & $7(50)$ & $48(51,6)$ & \multirow[t]{4}{*}{0,7} \\
\hline p.Phe508del heterozygous & $5(35,7)$ & $24(25,8)$ & \\
\hline Other & $2(14,3)$ & $16(17,2)$ & \\
\hline Unknown & $0(0)$ & $5(5,4)$ & \\
\hline \multicolumn{4}{|l|}{ Ethnicity } \\
\hline Mixed ancestry & $4(28,6)$ & $34(36,6)$ & \multirow[t]{4}{*}{0,9} \\
\hline White & $9(64,3)$ & $53(57,0)$ & \\
\hline Asian & $0(0)$ & $1(1,1)$ & \\
\hline Black African & $1(7,1)$ & $5(5,4)$ & \\
\hline
\end{tabular}

PI: Pancreatic Insufficient; PA: Pseudomonas; MRSA: Methicillin-resistant Staphylococcus aureus

\section{DISCUSSION:}

This study investigated the change in lung function and mortality of South African children and adolescents with CF over a 10-year period and examined the modifiable and nonmodifiable predictors of lung function decline in these patients. There was a non-significant improvement in the lung function of our study population over the 10-year study period, similar to the improvement in lung function reported previously by Morrow et al from the same centre during the 8-year period between January 1999 to December 2006 (2). This VBRNATOO3 MMed (Paediatrics) 
ongoing improvement in population lung function of South African patients with CF is encouraging and reflects continued improvement in holistic CF management at our centre.

With advancing age of our study population, we showed that PF declined accordingly over time. Importantly, the rate of PF decline was not significantly influenced by factors such as age of diagnosis, genotype, ethnicity, gender or infections. However, a lower FEV1 from age 6 years was associated with P.aeruginosa infection and increased mortality. This important observation, noted too in international CF registry data (26), implies that early life determinants of lung function play a critical role in predicting CF survival. Earlier acquisition of $P$. aeruginosa was the only predictor of poorer FEV1 at age 6 in our cohort, although causality cannot be determined on the basis of this study design. P. aeruginosa infection was not statistically associated with mortality in our study which is in contrast to international experience, likely due to small sample size and other unmeasured modifiable factors (27-29). Clinical interventions that focus on mitigating factors that influence early lung function and reduce mortality are needed. More sensitive tools to measure and monitor lung function in very young children must enter the routine clinical practice realm in order to identity at risk infants and children and address these modifiable factors.

Studies from high income countries have demonstrated an association between malnutrition and progression of lung disease (30). Similarly, our study showed a significant correlation between $\mathrm{BMI}$ and $\mathrm{FEV} 1$, and demonstrated that as pulmonary function declined with age, so too did BMI. Malnutrition in patients with CF may partly be caused by poor absorption due to pancreatic insufficiency $(30,31)$. Studies by Corey et al and Harun et al showed that pancreatic 
insufficiency was associated with a steeper decline in $\operatorname{FEV} 1(1,10)$. Our study showed no significant effects of pancreatic status on FEV1 at any age, which may reflect earlier detection and improved management of pancreatic insufficiency in our study population, thereby mitigating accelerated BMI decline and also preserving FEV1. The relationship between nutrition and pulmonary function in CF is a complex, multifactorial one. Poor absorption due to pancreatic insufficiency, anorexia, chronic suppurative lung disease, chronic inflammation with increased energy requirements and increased basal metabolic rate all contribute to malnutrition (30-32) (33). Malnutrition also reduces muscle mass resulting in reduced force of contraction of respiratory muscles and impaired lung function, making children with CF particularly vulnerable to infection and pulmonary inflammation (30-32) (33). One may thus deduce that, because of this multifactorial association between nutrition and FEV1, and the fact that FEV1 is strongly associated with mortality in patients with $\operatorname{CF}(3,7)$, malnutrition may ultimately impact on their survival (30).

The median age of diagnosis of CF in our study population was 5.5 months and we did not show a correlation between age of diagnosis and FEV1 scores at any age. This is surprising considering evidence of the positive impact of early diagnosis and NBS on CF nutrition, PF and other CF-related outcomes (34). Results of international studies have been inconsistent, with some studies indicating no difference in lung function of children with CF diagnosed early versus those diagnosed later (13-15), and other studies demonstrating better lung function in children with CF who were diagnosed at an early age $(16,17)$. In a SA study by Morrow et al (7), children with CF diagnosed before 1 year of age had less severe lung disease than those diagnosed after 5 years of age. An explanation for this contrasting observation may be that 
the majority of children in our more recent cohort were diagnosed relatively young thus eliminating any effect of delayed diagnosis age on pulmonary function. More research is needed to investigate the cost-benefit value of implementing CF NBS programmes in LMICs such as South Africa.

This study was limited by small sample size and that this was a single centre study. Despite including patients from both urbanised and more rural areas, it was conducted in the Western Cape which is one of the more developed provinces in South Africa. It involved study participants attending RCWMCH CF clinic, an institution which is relatively well resourced, compared to many other healthcare facilities in South Africa. Therefore, results may not be completely representative of South African children with CF. Another limitation is we were unable to measure or document socioeconomic modifiable factors determining pulmonary function and survival in this cohort. Factors such as household cigarette smoke or biomass fuel exposure, caregiver education, food security, household income and adherence to treatments were not accurately recorded in the medical records as these are difficult to quantify in a consistent and reliable way. We excluded 20 children who died before they were old enough to have PF testing. This highlights the importance and likelihood of other early life factors in determining CF survival in SA that were not examined in this study.

In conclusion, we demonstrated a positive trend of improving PF in our CF study population over the 10-year study period. However, rate of PF decline over time correlated with declining BMI but was similar regardless of age of CF diagnosis, genotype, gender or race. FEV1 at age 6 was the strongest predictor of mortality, and there was a weak association of lower FEV 1 
in those infected and colonised by $P$. aeruginosa . Identifying modifiable factors in infancy and early life that affect CF outcomes and improved tools to measure and monitor pulmonary function in young children are important practice changing priorities.

\section{ACKNOWLEDGEMENTS:}

None

\section{FUNDING:}

This research did not receive any specific grant from funding agencies in the public, commercial, or not-for-profit sectors.

\section{CONFLICT OF INTEREST:}

The authors have no conflict of interests related to the published work

\section{REFERENCES:}

1. Harun SN, Wainwright C, Klein K, Hennig S. A systematic review of studies examining the rate of lung function decline in patients with cystic fibrosis. Paediatric respiratory reviews. 2016;20:55-66.

2. Morrow BM, Argent AC, Zar HJ, Westwood AT. Improvements in lung function of a pediatric cystic fibrosis population in a developing country. Jornal de pediatria. 2008;84(5):403-9.

3. Heinzmann-Filho JP, Pinto LA, Marostica PJ, Donadio MV. Variation in lung function is associated with worse clinical outcomes in cystic fibrosis. Jornal brasileiro de pneumologia : publicacao oficial da Sociedade Brasileira de Pneumologia e Tisilogia. 2015;41(6):509-15.

4. Morgan WJ, Wagener JS, Yegin A, Pasta DJ, Millar SJ, Konstan MW. Probability of treatment following acute decline in lung function in children with cystic fibrosis is related to baseline pulmonary function. The Journal of pediatrics. 2013;163(4):1152-7.e2.

5. Ren CL, Rosenfeld M, Mayer OH, Davis SD, Kloster M, Castile RG, et al. Analysis of the associations between lung function and clinical features in preschool children with cystic fibrosis. Pediatric pulmonology. 2012;47(6):574-81.

6. Com G, Carroll JL, Castro MM, Tang X, Jambhekar S, Berlinski A. Predictors and outcome of low initial forced expiratory volume in 1 second measurement in children with cystic fibrosis. The Journal of pediatrics. 2014;164(4):832-8. 
7. Morrow BM, Argent AC, Distiller GB, Zar HJ, Westwood ATR. Rate of pulmonary function decline in South African children with cystic fibrosis. SAJCH. 2009;3:73-7.

8. Konstan MW, Morgan WJ, Butler SM, Pasta DJ, Craib ML, Silva SJ, et al. Risk factors for rate of decline in forced expiratory volume in one second in children and adolescents with cystic fibrosis. The Journal of pediatrics. 2007;151(2):134-9, 9.e1.

9. Cogen J, Emerson J, Sanders DB, Ren C, Schechter MS, Gibson RL, et al. Risk factors for lung function decline in a large cohort of young cystic fibrosis patients. Pediatric pulmonology. 2015;50(8):763-70.

10. Corey $\mathrm{M}$, Edwards L, Levison $\mathrm{H}$, Knowles $\mathrm{M}$. Longitudinal analysis of pulmonary function decline in patients with cystic fibrosis. The Journal of pediatrics. 1997;131(6):809-14. 11. Schibler A, Bolt I, Gallati S, Schoni MH, Kraemer R. High morbidity and mortality in cystic fibrosis patients compound heterozygous for 3905insT and deltaF508. The European respiratory journal. 2001;17(6):1181-6.

12. Kerem E, Viviani L, Zolin A, MacNeill S, Hatziagorou E, Ellemunter $H$, et al. Factors associated with FEV1 decline in cystic fibrosis: analysis of the ECFS patient registry. The European respiratory journal. 2014;43(1):125-33.

13. Sanders DB, Li Z, Laxova A, Rock MJ, Levy H, Collins J, et al. Risk factors for the progression of cystic fibrosis lung disease throughout childhood. Annals of the American Thoracic Society. 2014;11(1):63-72.

14. Siret D, Bretaudeau G, Branger B, Dabadie A, Dagorne M, David V, et al. Comparing the clinical evolution of cystic fibrosis screened neonatally to that of cystic fibrosis diagnosed from clinical symptoms: a 10-year retrospective study in a French region (Brittany). Pediatric pulmonology. 2003;35(5):342-9.

15. Sims EJ, Clark A, McCormick J, Mehta G, Connett G, Mehta A. Cystic fibrosis diagnosed after 2 months of age leads to worse outcomes and requires more therapy. Pediatrics. 2007;119(1):19-28.

16. Coffey MJ, Whitaker V, Gentin N, Junek R, Shalhoub C, Nightingale S, et al. Differences in Outcomes between Early and Late Diagnosis of Cystic Fibrosis in the Newborn Screening Era. The Journal of pediatrics. 2017;181:137-45.e1.

17. Slieker MG, van den Berg JM, Kouwenberg J, van Berkhout FT, Heijerman HG, van der Ent CK. Long-term effects of birth order and age at diagnosis in cystic fibrosis: a sibling cohort study. Pediatric pulmonology. 2010;45(6):601-7.

18. Taylor-Robinson DC, Smyth RL, Diggle PJ, Whitehead M. The effect of social deprivation on clinical outcomes and the use of treatments in the UK cystic fibrosis population: a longitudinal study. The Lancet Respiratory medicine. 2013;1(2):121-8.

19. Ong T, Schechter M, Yang J, Peng L, Emerson J, Gibson RL, et al. Socioeconomic Status, Smoke Exposure, and Health Outcomes in Young Children With Cystic Fibrosis. Pediatrics. 2017;139(2).

20. Collaco JM, Vanscoy L, Bremer L, McDougal K, Blackman SM, Bowers A, et al. Interactions between secondhand smoke and genes that affect cystic fibrosis lung disease. Jama. 2008;299(4):417-24.

21. Oates GR, Stepanikova I, Gamble S, Gutierrez HH, Harris WT. Adherence to airway clearance therapy in pediatric cystic fibrosis: Socioeconomic factors and respiratory outcomes. Pediatric pulmonology. 2015;50(12):1244-52. 
22. Reece E, Segurado R, Jackson A, McClean S, Renwick J, Greally P. Co-colonisation with Aspergillus fumigatus and Pseudomonas aeruginosa is associated with poorer health in cystic fibrosis patients: an Irish registry analysis. BMC pulmonary medicine. 2017;17(1):70.

23. Pentz A, Becker P, Masekela R, Coetzee O, Green RJ. The impact of chronic pseudomonal infection on pulmonary function testing in individuals with cystic fibrosis in Pretoria, South Africa. South African medical journal = Suid-Afrikaanse tydskrif vir geneeskunde. 2014;104(3):191-4.

24. B. ZMM. The South African Cystic Fibrosis Consensus Guidelines 5th Edition. 2017. 2017.

25. Quanjer PH, Stanojevic S, Cole TJ, Baur X, Hall GL, Culver BH, et al. Multi-ethnic reference values for spirometry for the 3-95-yr age range: the global lung function 2012 equations. The European respiratory journal. 2012;40(6):1324-43.

26. Sly PD, Wainwright CE. Preserving Lung Function: The Holy Grail in Managing Cystic Fibrosis. Annals of the American Thoracic Society. 2017;14(6):833-5.

27. Emerson J, Rosenfeld M, McNamara S, Ramsey B, Gibson RL. Pseudomonas aeruginosa and other predictors of mortality and morbidity in young children with cystic fibrosis. Pediatric pulmonology. 2002;34(2):91-100.

28. Henry RL, Mellis CM, Petrovic L. Mucoid Pseudomonas aeruginosa is a marker of poor survival in cystic fibrosis. Pediatric pulmonology. 1992;12(3):158-61.

29. Nixon GM, Armstrong DS, Carzino R, Carlin JB, Olinsky A, Robertson CF, et al. Clinical outcome after early Pseudomonas aeruginosa infection in cystic fibrosis. The Journal of pediatrics. 2001;138(5):699-704.

30. Souza dos Santos Simon MI, Drehmer $M$, de Abreu ESFA, Hoffmann A, Druck Ricachinewsky C, de Fonseca Andrade Procianoy E, et al. Association of nutritional status, plasma, albumin levels and pulmonary function in cystic fibrosis. Nutricion hospitalaria. 2011;26(6):1322-7.

31. Hauschild DB, Rosa AF, Ventura JC, Barbosa E, Moreira EAM, Ludwig Neto N, et al. Association of nutritional status with lung function and morbidity in children and adolescents with cystic fibrosis: a 36-month cohort study. Revista paulista de pediatria : orgao oficial da Sociedade de Pediatria de Sao Paulo. 2018;36(1):8.

32. Pedreira CC, Robert RG, Dalton V, Oliver MR, Carlin JB, Robinson P, et al. Association of body composition and lung function in children with cystic fibrosis. Pediatric pulmonology. 2005;39(3):276-80.

33. Pencharz PB, Durie PR. Pathogenesis of malnutrition in cystic fibrosis, and its treatment. Clinical nutrition (Edinburgh, Scotland). 2000;19(6):387-94.

34. Hoch H, Sontag MK, Scarbro S, Juarez-Colunga E, McLean C, Kempe A, et al. Clinical outcomes in U.S. infants with cystic fibrosis from 2001 to 2012. Pediatric pulmonology. 2018;53(11):1492-7. 


\section{UNIVERSITY OF CAPE TOWN}

Faculty of Health Sclences Human Research Ethlcs Commlttee

Room E53-46 Old Maln Bullding Groote Schuur Hospltal Observatory 7925 Observatory 7925
Telephone [021] 4066626 Emall: shuretta, themasfluct.ac,za
Website: www. health.uct.aciza/fhs/research/humanethics/forms

29 November 2017

HREC REF: $830 / 2017$

\section{Prof B Morrow}

Paedlatrics

5th floor ICH Building

Red Cross War Memorial Children's Hospltal

Dear Prof Morrow

PROJECT TITLE: HOW HAS THE LUNG FUNCTION AND MORTALITY OF CHILDREN AND ADOLESCENTS WITH CYSTIC FIBROSIS CHANGED OVER 10 YEARS, AND WHAT WERE THE DETERMINANTS OF THIS CHANGE? (MMed-candidate-Dr N Vandenbroucke) Thank you for submitting your study to the Faculty of Health Sclences Human Research Ethics
Committee.

It is a pleasure to Inform you that the HREC has formally approved the above-mentioned study.

\section{Approval is granted for one year untll the 30 November 2018.}

Please submit a progress form, using the standardised Annual Report Form if the study continues beyond the approval period. Please submit a Standard Closure form if the study is completed within
the approval perlod.

(Forms can be found on our website: www.health.uct.ac.za/fhs/research/humanethlcs/forms)

Please quote the HREC REF In all your correspondence. Please note that the ongoing ethical conduct of the study remains the responsibility of the principal
investigator.

Please note that for all studles approved by the HREC, the principal investigator must obtain appropriate institutional approval, where necessary, before the research may occur.

The HREC acknowiedge that the student Dr Natalie Vandenbroucke will also be Involved in this study.

\section{Yours sincerely}

Signature Removed

\section{PROFESSOR M BLOCKMAN}

CHAIRPERSON, FHS HUMAN RESEARCH ETHICS COMMITTEE

Federal WIde Assurance Number: FWA00001637.

Institutional Revlew Board (IRB) number: IRB00001938

This serves to conflrm that the Unlversity of Cape Town Human Research Ethlcs Committee complies to the Ethics Standards for Clinical Research with a new drug in patients, based on the Medical 
APPENDIX 2: Questionnaire/data capture instrument(s)

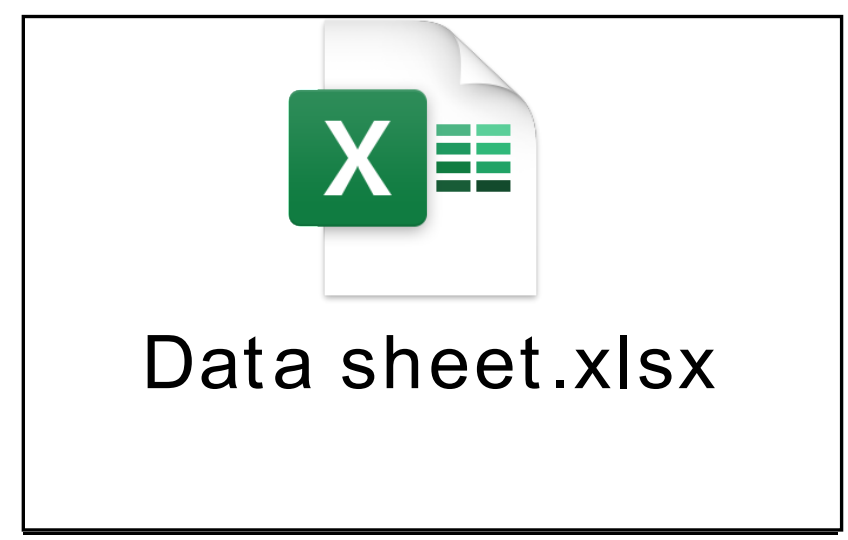




\section{APPENDIX 3: AUTHOR GUIDELINES South African Medical Journal (SAMJ)}

\section{Research}

Guideline word limit: 4000 words

Research articles describe the background, methods, results and conclusions of an original research study. The article should contain the following sections: introduction, methods, results, discussion and conclusion, and should include a structured abstract (see below). The introduction should be concise - no more than three paragraphs - on the background to the research question, and must include references to other relevant published studies that clearly lay out the rationale for conducting the study. Some common reasons for conducting a study are: to fill a gap in the literature, a logical extension of previous work, or to answer an important clinical question. If other papers related to the same study have been published previously, please make sure to refer to them specifically. Describe the study methods in as much detail as possible so that others would be able to replicate the study should they need to. Results should describe the study sample as well as the findings from the study itself, but all interpretation of findings must be kept in the discussion section, which should consider primary outcomes first before any secondary or tertiary findings or post-hoc analyses. The conclusion should briefly summarise the main message of the paper and provide recommendations for further study.

Select figures and tables for your paper carefully and sparingly. Use only those figures that provided added value to the paper, over and above what is written in the text.

Do not replicate data in tables and in text .

\section{Structured abstract}

- This should be 250-400 words, with the following recommended headings:

- Background: why the study is being done and how it relates to other published work.

Objectives: what the study intends to find out

- Methods: must include study design, number of participants, description of the intervention, primary and secondary outcomes, any specific analyses that were done on the data.

- Results: first sentence must be brief population and sample description; outline the results according to the methods described. Primary outcomes must be described first, even if they are not the most significant findings of the study.

- Conclusion: must be supported by the data, include recommendations for further study/actions.

- Please ensure that the structured abstract is complete, accurate and clear and has been approved by all authors.

- Do not include any references in the abstracts.

Here is an example of a good abstract.

\section{Main article}

All articles are to include the following main sections: Introduction/Background, Methods, Results, Discussion, Conclusions. 
The following are additional heading or section options that may appear within these:

- Objectives (within Introduction/Background): a clear statement of the main aim of the study and the major hypothesis tested or research question posed

- Design (within Methods): including factors such as prospective, randomisation, blinding, placebo control, case control, crossover, criterion standards for diagnostic tests, etc.

- Setting (within Methods): level of care, e.g. primary, secondary, number of participating centres.

- Participants (instead of patients or subjects; within Methods): numbers entering and completing the study, sex, age and any other biological, behavioural, social or cultural factors (e.g. smoking status, socioeconomic group, educational attainment, co-existing disease indicators, etc)that may have an impact on the study results. Clearly define how participants were enrolled, and describe selection and exclusion criteria.

- Interventions (within Methods): what, how, when and for how long. Typically for randomised controlled trials, crossover trials, and before and after studies.

- Main outcome measures (within Methods): those as planned in the protocol, and those ultimately measured. Explain differences, if any.

\section{Results}

- Start with description of the population and sample. Include key characteristics of comparison groups.

- Main results with (for quantitative studies) 95\% confidence intervals and, where appropriate, the exact level of statistical significance and the number need to treat/harm. Whenever possible, state absolute rather than relative risks.

- Do not replicate data in tables and in text.

- If presenting mean and standard deviations, specify this clearly. Our house style is to present this as follows:

- E.g.: The mean (SD) birth weight was 2500 (1210) g. Do not use the \pm symbol for mean (SD).

- Leave interpretation to the Discussion section. The Results section should just report the findings as per the Methods section.

\section{Discussion}

Please ensure that the discussion is concise and follows this overall structure - sub-headings are not needed:

- Statement of principal findings

- Strengths and weaknesses of the study

- Contribution to the body of knowledge

- Strengths and weaknesses in relation to other studies

- The meaning of the study - e.g. what this study means to clinicians and policymakers

- Unanswered questions and recommendations for future research

\section{Conclusions}

This may be the only section readers look at, therefore write it carefully. Include primary conclusions and their implications, suggesting areas for further research if appropriate. Do not go beyond the data in the article. 